Research Article

\title{
Experimental Investigation on Deformation and Strength Behavior of Marble with the Complex Loading-Unloading Stress Path
}

\author{
Chen Chen $\mathbb{D},{ }^{1,2}$ Lipeng Liu $\mathbb{D}^{1},{ }^{2}$ and Yu Cong $\mathbb{D}^{3}$ \\ ${ }^{1}$ School of Engineering and Technology, China University of Geosciences (Beijing), Beijing 100083, China \\ ${ }^{2}$ State Key Laboratory of Simulation and Regulation of Water Cycle in River Basin China Institute of Water Resources and \\ Hydropower Research, Beijing 100048, China \\ ${ }^{3}$ School of Civil Engineering, Qingdao University of Technology, Qingdao 266033, China
}

Correspondence should be addressed to Lipeng Liu; liulip@iwhr.com

Received 4 August 2020; Revised 27 September 2020; Accepted 14 October 2020; Published 4 November 2020

Academic Editor: Fengqiang Gong

Copyright (C) 2020 Chen Chen et al. This is an open access article distributed under the Creative Commons Attribution License, which permits unrestricted use, distribution, and reproduction in any medium, provided the original work is properly cited.

\begin{abstract}
The excavation of deep tunnel in rock mass undergoes complex loading and unloading stress paths, resulting in rib spalling, flaking, and even severe rockburst disasters. Based on the variation law of the stress path of the surrounding rock, laboratory tests of rock mechanics are designed, and the deformation and strength behavior of marble with different initial confining pressure and unloading rates are systematically studied. By introducing strain increment, the characteristic stress, and the dilatancy index, the rock's dilatancy and brittleness under different unloading conditions are quantitatively analyzed. During unloading, the energy transformation mechanism of rock is described, and the law of deformation and failure is discussed based on characteristic energy. The rock failure strength fitting formula is given by applying the Mogi-Coulomb criterion and elastic strain energy criterion. The advantages of the elastic strain energy criterion are theoretically explained. This study shows that comprehensive consideration of the complex stress paths, confining pressure levels, and the loading-unloading rates of surrounding rock is an effective way to accurately study unloading rock characteristics. The results can provide theoretical basis for stability analysis of high-stress underground engineering.
\end{abstract}

\section{Introduction}

The hard rock stability during excavation under the high in situ stress condition has been a concern in engineering and academic circles. Excavation of underground caverns is essentially a process in which the surrounding rock changes rapidly from a three-way stress state to a one-way or twoway stress state. This process is very complicated. The spatial stress redistribution of tunnels changes with different excavation methods. Generally, it can be summarized as the process of circumferential loading-radial unloading and three-way unloading $[1,2]$. Due to the rapid transformation of stress and the sharp release of energy in the rock mass, the surrounding rock has different damage characteristics than that of low-stress underground caverns. Based on wide underground engineering experiences and experimental investigations, some researchers studied the failure behaviors of the unloading rock including spalling $[3,4]$ and rockburst [5]. These destructions present a major threat to underground structures and workers' safety, and it is necessary to study the strength and deformation behavior of rock to ensure long-term stability of excavations at depth. Under the unloading condition, the strength, deformation, and failure characteristics of the rock are different from those in the traditional simple loading environment. For deep tunnels, rock mass undergoes complex loadingunloading stress paths during excavation, which control the deformation and failure mode of the rock in a high-stress condition. Many laboratory rock mechanics research studies about stress paths have been carried out. In the previous 
studies, unloading tests based on different stress paths mainly include three methods $[1,6]$ : (1) unloading confining pressure $\sigma_{3}$ with axial pressure $\sigma_{1}$ constant; (2) unloading $\sigma_{3}$ and loading $\sigma_{1}$; and (3) unloading $\sigma_{3}$ and $\sigma_{1}$. There are some limitations in those tests. For example, the stress path design of rock always depends on scholars' perception of the stress state or trend of unloading rock. In fact, the evolution law of stress paths depends not only on the occurrence environment and excavation method but also on the different locations along the surrounding rock of tunnels, such as the sidewall and roof rock mass. It is significant to study the unloading rock based on the different locations of the tunnel.

The unloading rate of rock mass is obviously different for different construction progress. The disasters occurring in the construction are generally related to the fast construction without in-time reinforcement. The deformation of rock mass during excavation has a strong space effect [7]. It is one of the effective methods to reduce the geological hazard risk of a high-stress tunnel by controlling the excavation speed and combining with necessary support measures. Therefore, the study on the mechanical properties of rock at different unloading rates, especially under the high-stress condition, has important theoretical and engineering significance. In the recent years, the unloading rate has become an important research field in rock mechanics. Some researchers have studied the deformation, strength, and energy characteristics of the rock at different loading and unloading rates through laboratory tests [7-9], which proves that the unloading rate is an important factor affecting physical and mechanical properties of the rock.

According to thermodynamics, energy conversion is the essential characteristic of the physical process of matter. Rock failure is a state instability driven by energy. Up to now, many scholars have studied the mechanical behavior of unloading rock from the viewpoint of energy, such as the mechanism of strain energy transformation during the unloading process of rock [10], the rock failure criterion based on the fracture energy $[11,12]$ and the rock failure characteristics due to energy release during unloading $[13,14]$. Also, the strength and deformation law of rock mass are always the theoretical basis of engineering stability analysis. For a long time, rock strength and failure criteria based on classical elastic-plastic theory have been the basis for judging rock failure in actual engineering [15]. For unloading rock mass, scholars have successively applied many empirical criteria and modified strength criterion of the Mohr-Coulomb theory, such as the Mogi-Coulomb criterion [6], the strength criteria of octahedral shear stress with three parameters [16], Mohr strength criterion of power function [17], modified D-P criterion based on the doublefold reduction method [18], and CWFS failure criterion $[19,20]$. However, those criteria cannot reflect the rock failure characteristics very well and cannot reflect the intrinsic mechanism of rock unloading failure; that is, energy transformation is the essential attribute of the physical process of matter [17].

There have been many studies on the strength, deformation, and failure characteristics of rock under the unloading condition, but most of them focused on one stress path or did not consider of the variation of stress paths of the surrounding rock after excavation in actual engineering situations. Moreover, it is difficult to effectively analyze the complex stress changes and overall failure behavior of unloading rock by many existing criteria [21]. In this paper, considering the variation law of the stress path of rock, we carry out rock mechanics tests on the marble of Jinping II Hydropower Station with different initial confining pressures and different axial loading-lateral unloading rates. Then, we systematically study the failure, dilatancy, energy, and strength characteristics of rock under high-stress unloading conditions. Furthermore, we quantitatively describe the deformation and energy transformation process of rock samples at different confining pressures and unloading rates. Based on the Mohr-Coulomb criterion, Mogi-Coulomb criterion, and elastic strain energy criterion, we study the rock strength with complex loading and unloading stress paths and theoretically express the difference in mechanical properties of rock mass under loading and unloading conditions with relatively simple mathematical formulas [21]. The results can provide a theoretical basis for the preliminary design and safe construction of deep tunnels.

\section{Experimental Material and Testing Methodology}

2.1. Physical Properties of the Tested Rock. The marble samples used in tests were cored from a fresh intact rock block in the region of the tunnel face of stake SK $09+300$, which is located in a drainage hole. The investigated rock samples are gray-white marbles, which belong to the Baishan group $\left(\mathrm{T}_{2} \mathrm{~b}\right)$ of the Triassic strata. Table 1 shows the mineralogical composition of Jinping T2b marble, in which the mineral composition of dolomite is more than $88.0 \%$. Cylindrical rock samples were cored by a drill with an inner diameter of $50 \mathrm{~mm}$. The diameter of the samples was $48.9-49.5 \mathrm{~mm}$, and their length was $98.9-103.2 \mathrm{~mm}$. The average natural density was $2.721 \mathrm{~g} / \mathrm{cm} 3$, and the dry density was $2.685 \mathrm{~g} / \mathrm{cm} 3$. The wave velocity varied from $5338 \mathrm{~m} / \mathrm{s}$ to $6354 \mathrm{~m} / \mathrm{s}$.

2.2. Testing Methodology. In a deep-buried rock mass, the excavation and advancement of a tunnel face result in the disturbance and redistribution of the primary in situ stress field. Excavation of the surrounding rock is a process of loading and unloading $[22,23]$. The tunnel sidewall and roof rock mass of Jinping II Hydropower Station undergo complex stress paths while advancing the tunnel face [24]. The deviatoric stresses in the tunnel wall and roof increase continuously within a diameter range $(D$, where $D=7.2 \mathrm{~m})$ behind the working face, and the increase is faster closer to the tunnel face. After the working face passes, the deviatoric stresses in the tunnel roof significantly decrease and remain near the analytical solution of the plane strain (32 MPa). Meanwhile, the deviatoric stresses in the tunnel wall increase sharply and tend to be constant gradually within 2D away from the working face. This reflects the simultaneous 
TABLE 1: Mineralogical composition of Jinping $\mathrm{T}_{2} \mathrm{~b}$ marble.

\begin{tabular}{lccc}
\hline Minerals & Calcite & Dolomite & Mica \\
\hline Mineral content (\%) & $8.2-9.0$ & $88.0-92.2$ & $0.3-0.5$ \\
\hline
\end{tabular}

changes in radial unloading and circumferential loading of the rock as the tunnel face advances. Based on the deviatoric stress distribution along the surrounding rock and its two different stress paths shown in Figure 1, we perform unloading triaxial tests with $\left(\sigma_{1}-\sigma_{3}\right)$ constant and unloading confining-loading axial pressure tests with $\left(\sigma_{1}-\sigma_{3}\right)$ increasing continuously. Thus, we can study deformation, strength, and failure characteristics of the rock, and these results are more consistent with the actual excavation process of underground caverns.

Step 1: the rock samples are first kept at hydrostatic pressure $\sigma_{3}^{0}$, which is set to $10 \mathrm{MPa}, 20 \mathrm{MPa}$, or $40 \mathrm{MPa}$. These confining pressure values reflect the minor principal stress in the in situ stress field at the different stakes in Jinping II Hydropower Station's drainage hole.

Step 2: the axial $\sigma_{1}$ stress is, then, incrementally increased to the target value. In these tests, the axial stress $\sigma_{1}$ is loaded to $0.85 \sigma_{(10)}, 0.5 \sigma_{(10)}, 0.85 \sigma_{(20)}, 0.5 \sigma_{(20)}$, $0.85 \sigma_{(40)}$, and $0.5 \sigma_{(40)}$, which are approximately $85 \%$ or $50 \%$ of the peak strength of different confining pressures of Jinping marble, as shown in Table 2.

Step 3: different loading-unloading methods and rates are used for different confining pressure tests. When the axial pressure is $0.85 \sigma$, there are two different stress path conditions (Table 2): (1) the confining pressure and axial stress are unloaded at a rate of $0.1 \mathrm{MPa} / \mathrm{s}$ until the sample is broken; (2) the confining pressure and axial stress are unloaded at a rate of $0.5 \mathrm{MPa} / \mathrm{s}$ until the sample is broken. When the confining pressure is $0.5 \sigma$, there are also two different stress path conditions (Table 2): (1) the confining pressure is unloaded at a rate of $0.1 \mathrm{MPa} / \mathrm{s}$, while the axial stress is increased at a rate of $0.5 \mathrm{MPa} / \mathrm{s}$ until the sample is broken; (2) the confining pressure is unloaded at a rate of $0.5 \mathrm{MPa} / \mathrm{s}$, while the axial stress is increased at a rate of $0.5 \mathrm{MPa} / \mathrm{s}$ until the sample is broken.

Based on these stress variations, a series of mechanical texts of marble were presented. We carried out conventional triaxial tests and complex loading-unloading stress path tests, respectively. The triaxial tests can provide a reference for the unloading tests. In the loading test, TAW-2000 triaxial rigid testing machine is used, and the confining pressure of rock is set to $10 \mathrm{MPa}, 20 \mathrm{MPa}$, or $40 \mathrm{MPa}$. A schematic diagram of the testing stress path is shown in Figure 2(a). Meanwhile, complex loading-unloading stress path tests of the samples were designed by analyzing the actual tunnel excavation process in Jinping. A schematic diagram of the testing stress path is shown in Figure 2(b). The process is summarized as follows.

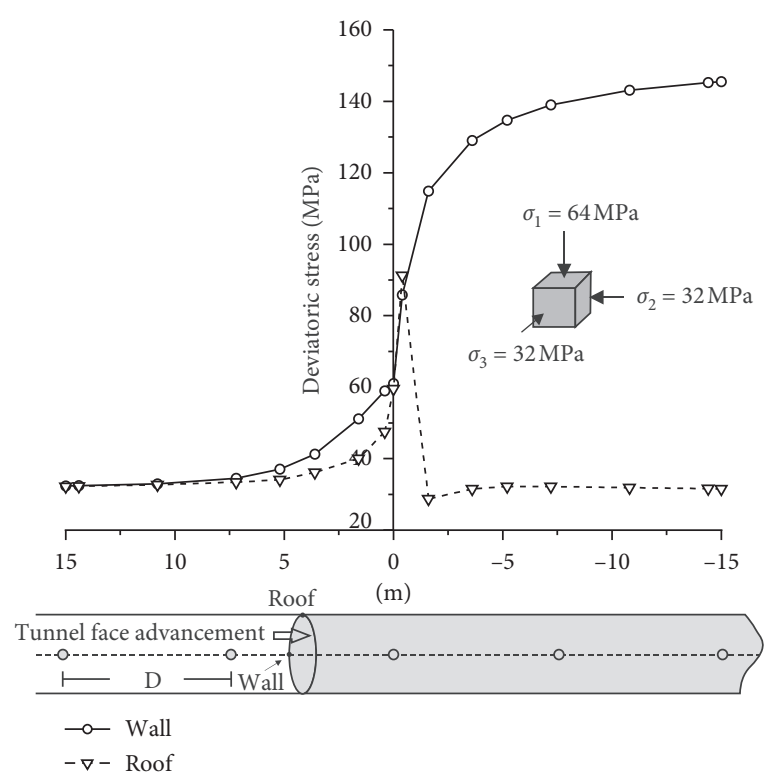

Figure 1: Deviatoric stresses at different locations along the surrounding rock (modified from the work of Liu et al., 2013).

\section{Results and Discussion}

3.1. Loading Test Results. Triaxial compression tests were performed under various confining pressures. Stress-strain curves are presented in Figure 3 for different values of confining pressures: $10 \mathrm{MPa}, 20 \mathrm{MPa}$, and $40 \mathrm{MPa}$. The loading test results are shown in Table 3. Based on these tests results, the mechanical properties of marble can be summarized as follows:

(1) The marble samples present typical elasto-brittleplastic characteristics in conventional triaxial confining pressure tests. With the increase in confining pressure, the peak strength point gradually moves backward, and the yield stage before the peak becomes obvious; meanwhile, the rock gradually transforms from brittle to ductile.

(2) The stress-strain curves present an approximate linear relationship before the peak strength. This is followed by a significant stress drop, and the specimens show brittle failure with a certain residual strength value.

(3) The peak strength and residual strength of the rock increase with larger initial confining pressures, mainly because the bearing capacity of the rock is strengthened with this increase in confining pressure.

(4) The research results of Li et al. [25] and Wang et al. [26] showed that the critical point of the brittle and ductile transition of marble in Jinping II Hydropower Station was $40 \mathrm{MPa}$. The test results found that the Jinping marble still presented brittleness under a $40 \mathrm{MPa}$ confining pressure. 
TABLE 2: Settings for confining pressure and axial stress in complex loading-unloading stress tests (negative values indicate unloading; positive values indicate loading).

\begin{tabular}{lcccc}
\hline Sample number & Initial confining pressure $\sigma_{3}^{0}(\mathrm{MPa})$ & Initial axial pressure $\sigma_{1}(\mathrm{MPa})$ & Stress rate of $\sigma_{3}(\mathrm{MPa} / \mathrm{s})$ & $\mathrm{Stress}$ rate of $\sigma_{1}(\mathrm{MPa} / \mathrm{s})$ \\
\hline 10 & & $0.85 \sigma(10)$ & -0.1 & -0.1 \\
11 & 10 & & -0.5 & -0.5 \\
12 & & $0.5 \sigma(10)$ & -0.1 & +0.5 \\
13 & & & -0.5 & +0.5 \\
14 & 20 & $0.85 \sigma(10)$ & -0.1 & -0.1 \\
15 & & & -0.5 & -0.5 \\
16 & & $0.5 \sigma(10)$ & -0.1 & +0.5 \\
17 & 40 & & -0.5 & +0.5 \\
20 & & $0.85 \sigma(10)$ & -0.1 & -0.1 \\
22 & & & -0.5 \\
23 & & $0.5 \sigma(10)$ & -0.1 & +0.5 \\
25 & & & -0.5 & +0.5 \\
\hline
\end{tabular}

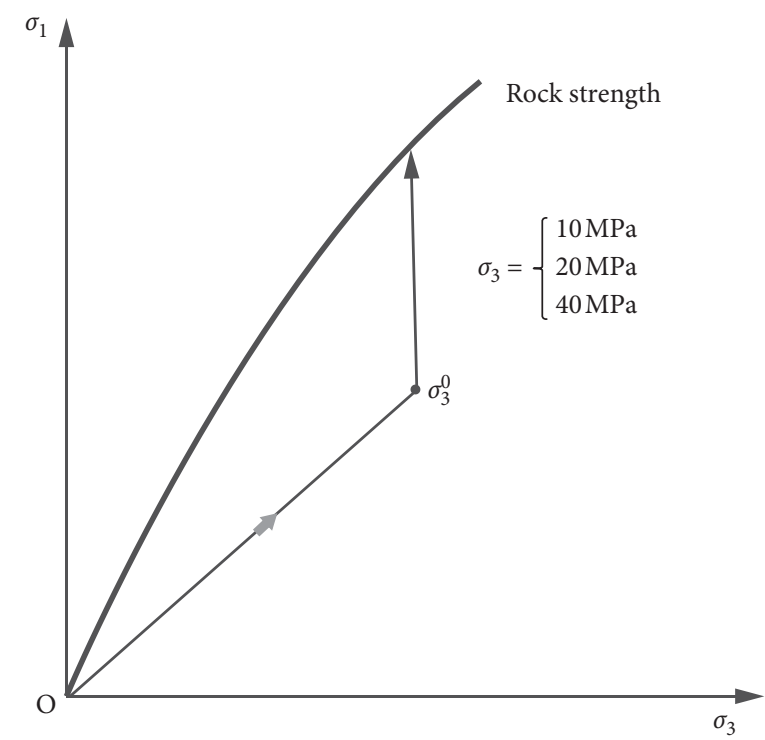

(a)

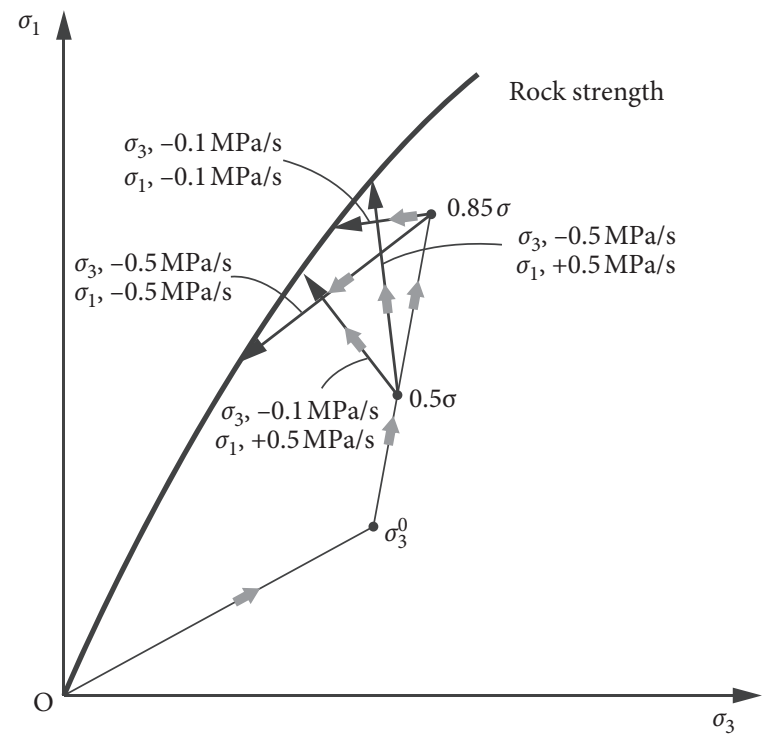

(b)

FIGURE 2: Schematic diagram of the tested stress paths: (a) conventional triaxial tests; (b) complex loading-unloading stress tests.

\subsection{Unloading Test Results}

3.2.1. Stress-Strain Characteristics. In the present study, 12 marble specimens were tested. Figures 4-6 show the relationship between the deviatoric stress $(\sigma 1-\sigma 3)$ and strains (axial, lateral, and volumetric) of samples. As can be seen from Figures 4-6, the stress-strain curves show a near-linear relationship before the peak strength. After reaching the peak strength, the lateral, axial, and volumetric strain increase rapidly, and the samples change from a compressed state to a dilatancy state. The deviatoric stress of the rock is significantly reduced and the stress drops. At the same time, the sound of brittle fracturing can be heard at the test site; that is, the rock samples of the unloading confining pressure test show obvious brittleness. In the following discussion, the influence of initial confining pressure, loading and unloading rates, and the stress paths on rock dilatancy, failure, energy, and strength characteristics is studied.
3.2.2. Dilatancy Characteristics. Based on the stress-strain curve, the process from the unloading starting point to the residual strength is divided into two stages: the unloading starting point to the peak strength stage and the peak strength to the residual strength stage. The dilatancy of unloading rock is investigated by analyzing strain increment, characteristic stress, and dilatancy parameter.

1. Strain increment characteristics: Figures 7 and 8 show the variation of axial strain increment $\Delta \varepsilon_{1}$ and lateral strain increment $\Delta \varepsilon_{3}$ under complex loading and unloading stress paths. The following points are observed:

(1) Compared to lateral strain increment $\Delta \varepsilon_{3}$, the axial strain increment $\Delta \varepsilon_{1}$ is smaller from the unloading starting point to the residual strength stage. Meanwhile, the lateral strain increment $\Delta \varepsilon_{3}$ is generally larger than $\Delta \varepsilon_{1}$, which indicates that the lateral dilatancy phenomenon is obvious with a lower confining pressure. Moreover, the failure of 


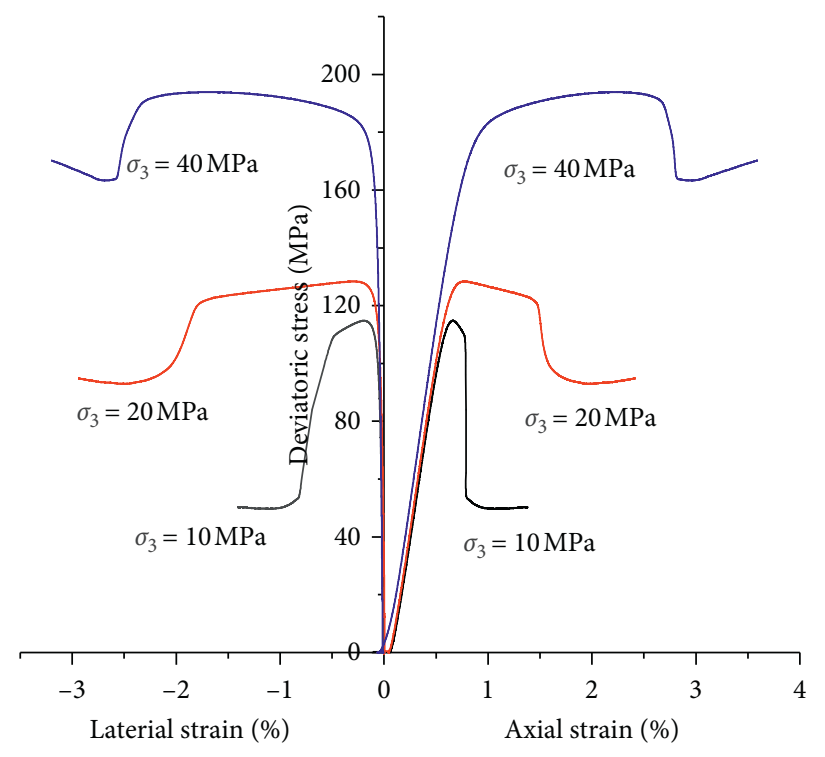

Figure 3: Stress-strain curves in triaxial compression tests.

TABLE 3: Test results of different samples.

\begin{tabular}{|c|c|c|c|c|c|}
\hline \multirow[b]{2}{*}{$\begin{array}{l}\text { Sample } \\
\text { number }\end{array}$} & \multirow[b]{2}{*}{ Test category } & \multirow[b]{2}{*}{$\begin{array}{l}\text { Peak strength } \\
\qquad(\mathrm{MPa})\end{array}$} & \multirow[b]{2}{*}{$\begin{array}{c}\text { Confining pressure of peak } \\
\text { strength }(\mathrm{MPa})\end{array}$} & \multicolumn{2}{|c|}{ Peak energy $\left(\mathrm{MJ} / \mathrm{m}^{3}\right)$} \\
\hline & & & & $\begin{array}{c}\text { Elastic strain } \\
\text { energy } \\
U_{e}\end{array}$ & $\begin{array}{c}\text { Dissipating strain } \\
\text { energy } \\
U_{d}\end{array}$ \\
\hline 8 & \multirow{8}{*}{ Triaxial compression test } & 114.06 & 10 & 0.072 & 0.047 \\
\hline 7 & & 128.35 & 20 & 0.082 & 0.052 \\
\hline 5 & & 198.17 & 40 & 0.124 & 0.080 \\
\hline 10 & & 98.823 & 2.4 & 0.059 & 0.034 \\
\hline 11 & & 97.856 & 0 & 0.051 & 0.043 \\
\hline 12 & & 95.26 & 2.2 & 0.053 & 0.124 \\
\hline 13 & & 74.27 & 0 & 0.034 & 0.108 \\
\hline 14 & & 113.55 & 9.1 & 0.071 & 0.047 \\
\hline 15 & \multirow{7}{*}{$\begin{array}{l}\text { Complex loading-unloading } \\
\text { stress test }\end{array}$} & 115.85 & 5.0 & 0.065 & 0.045 \\
\hline 16 & & 118.71 & 10.15 & 0.075 & 0.165 \\
\hline 17 & & 105.74 & 0 & 0.061 & 0.118 \\
\hline 20 & & 137.34 & 5.0 & 0.110 & 0.066 \\
\hline 22 & & 138.14 & 21.3 & 0.088 & 0.056 \\
\hline 23 & & 177.07 & 22.0 & 0.144 & 0.351 \\
\hline 25 & & 127.61 & 11.2 & 0.088 & 0.245 \\
\hline
\end{tabular}

rock samples is the result of strong dilatancy. The strain increment after the peak strength is significantly higher than that before the peak strength, which indicates that the integration of microcracks in the rock increases the dilatancy after the peak strength.

(2) With the increase in unloading rates, $\Delta \varepsilon_{1}$ decreases and $\Delta \varepsilon_{3}$ increases, which indicates that, with the increase of unloading rates, the time from peak strength to residual strength is shorter; that is, a higher unloading rate will shorten the time for rock to meet the current stress environment through self-adjustment, and the process of microcracks generation, development, and mutual fusion cannot be completed in sufficient time, leading to the higher deformation modulus. Thus, the rock shows more obvious brittleness, and the dilatancy increases accordingly. This also shows that, in deep underground engineering projects, with the faster excavation of rock mass or the larger single-cycle footage of the drilling and blasting method, the surrounding rock is more vulnerable to failure due to brittleness and even to a severe rockburst disaster.

(3) The unloading strain increment is larger with a higher initial unloading confining pressure. This is because under the initial compact environment, as the confining pressure increases, new microcracks 


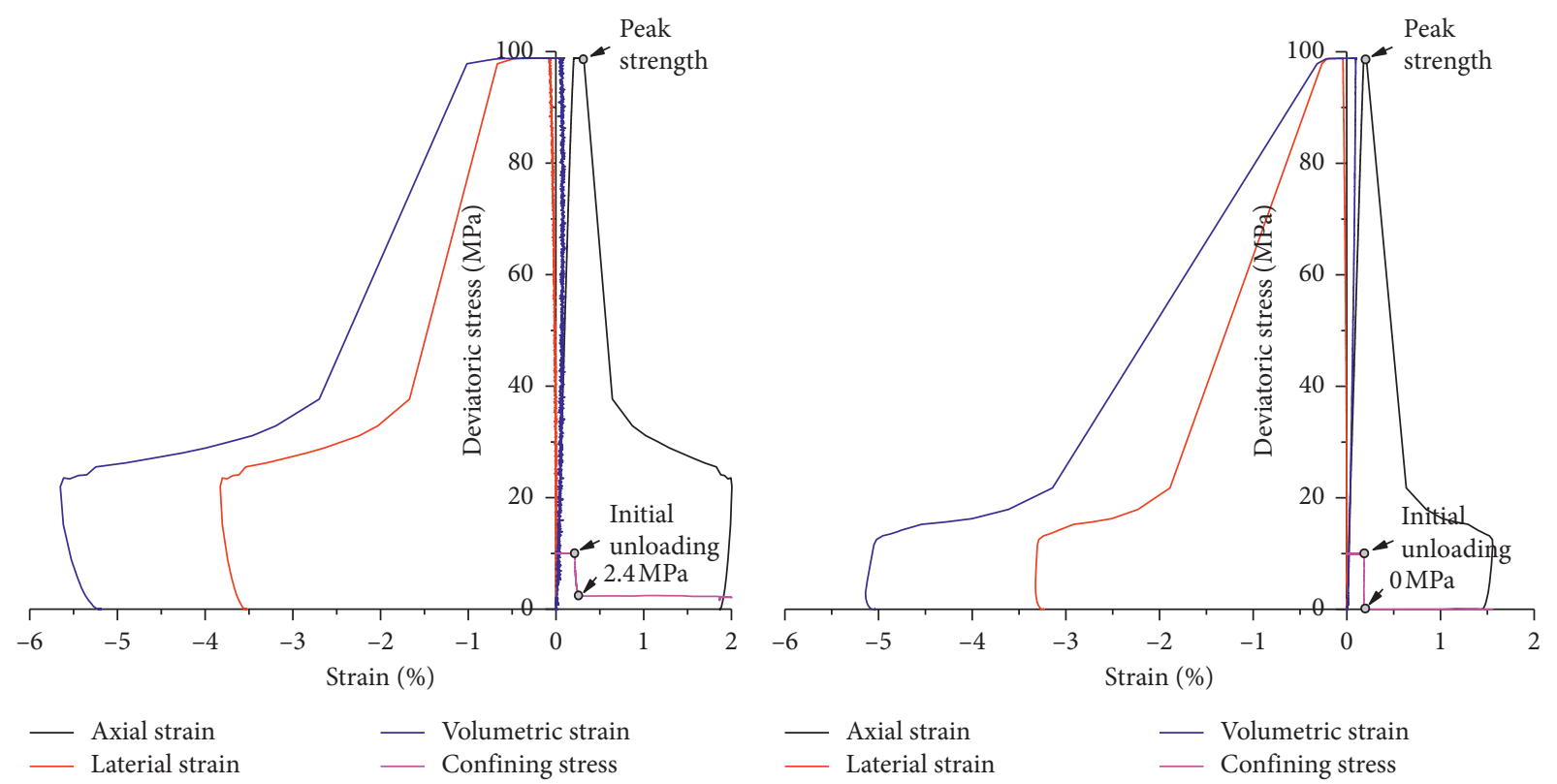

(a)

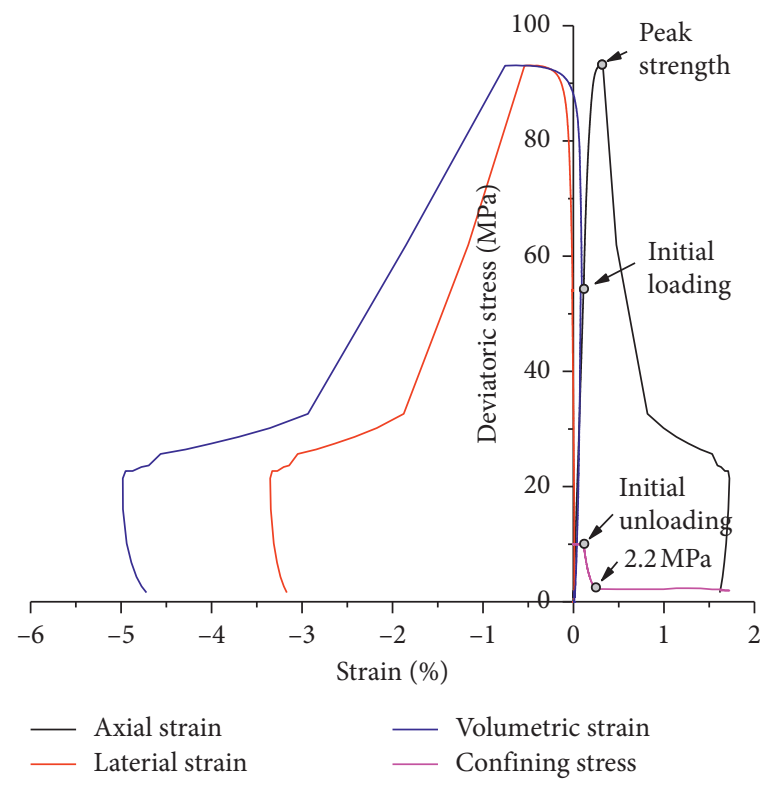

(c)

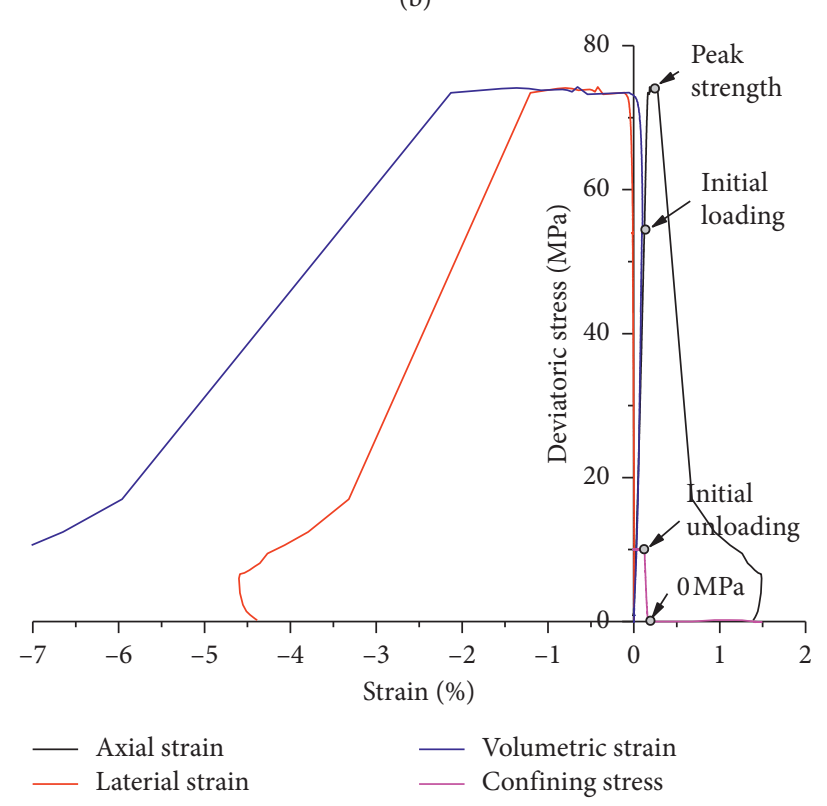

(d)

FIGURE 4: Stress-strain curves in complex loading-unloading stress tests (confining pressure: $10 \mathrm{MPa}$ ): (a) sample 10; (b) sample 11; (c) sample 12; and (d) sample 13.

are more likely to occur or existing microcracks are intensified, which leads to a sharp increase in brittleness.

(4) The strain increment varies with different stress paths. Under the unloading confining-loading axial pressure stress path, the axial strain increment before the peak strength is relatively large. This is because the initial unloading level under this path is lower and the axial pressure needs to be greater to reach the peak strength. At such a time, the corresponding $\Delta \varepsilon_{1}$ value is relatively large.
2. Stress characteristics: under different stress paths and unloading velocities, the initial yield stress $\left(\sigma_{c d}\right)$, peak stress $\left(\sigma_{f}\right)$, and residual stress $\left(\sigma_{r}\right)$ corresponding to the unloading starting point, peak strength point, and residual strength point are shown in Table 4 . The stress-confining pressure curves are shown in Figure 9.

Under different stress paths and unloading velocities, the characteristic stress increases with the increase in confining pressure. This is because the higher confining pressure effectively inhibits the development of internal cracks, resulting in an increase in the cohesive force of the rock 


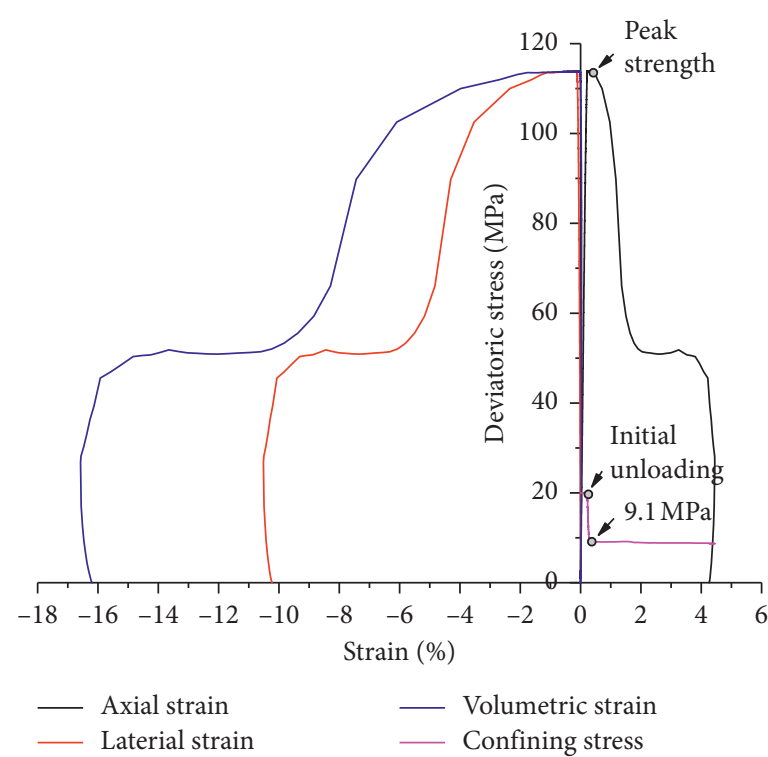

(a)

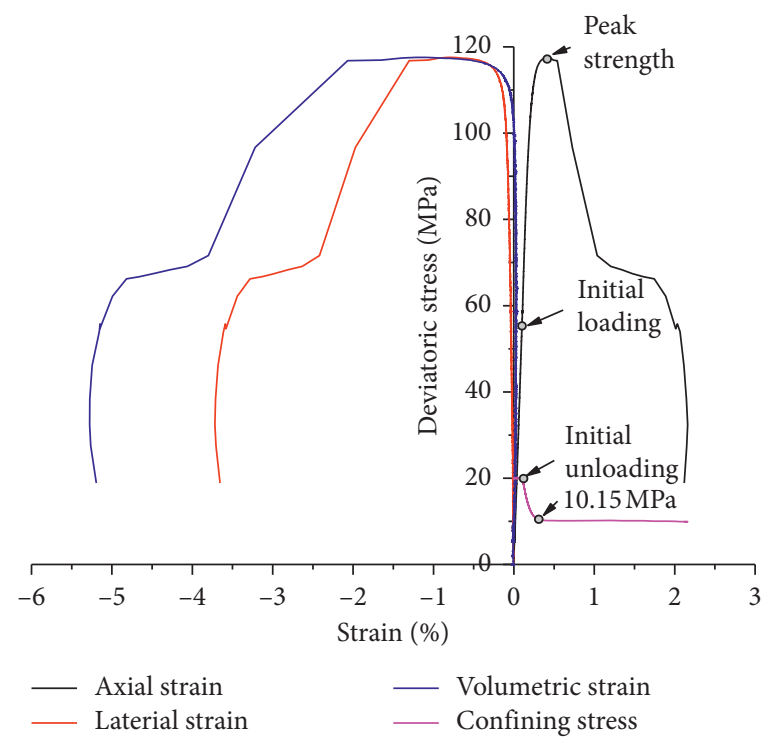

(c)

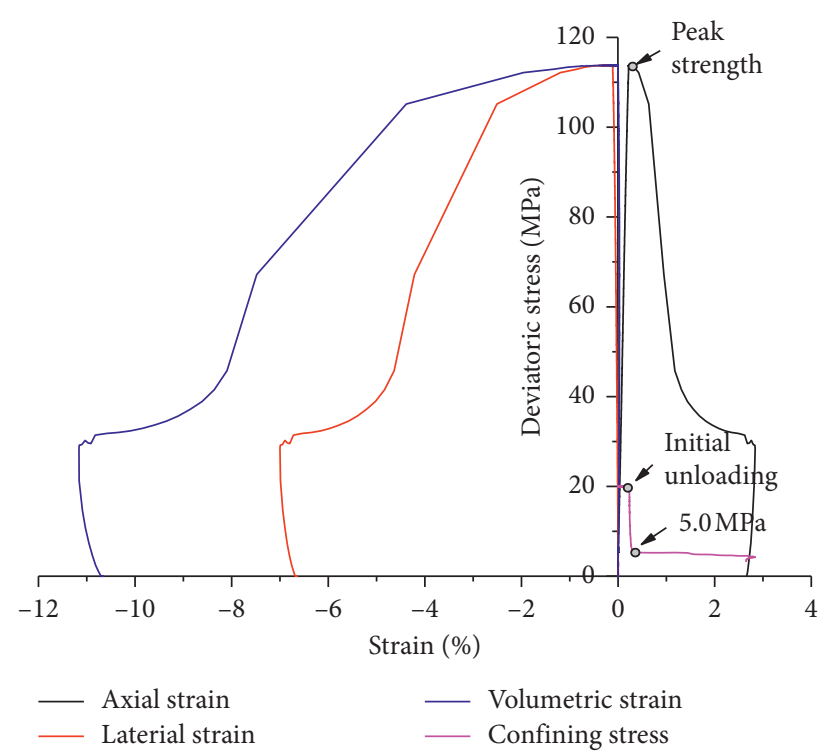

(b)

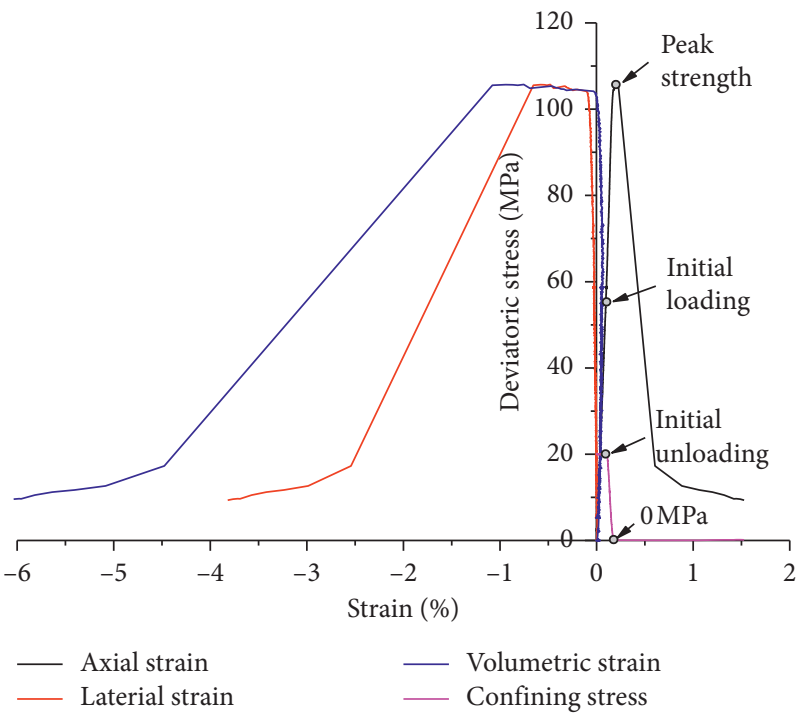

(d)

FiguRE 5: Stress-strain curves in complex loading-unloading stress tests (confining pressure: $20 \mathrm{MPa}$ ): (a) sample 14; (b) sample 15; (c) sample 16; and (d) sample 17.

samples. The peak stress and residual stress are smaller with larger unloading rates. Therefore, the increase in unloading rates accelerates rock deformation and failure. Under the same initial confining pressure and unloading rate, the characteristic stress under the unloading confining-loading axial pressure stress path is generally smaller than that under the unloading confining pressure path, indicating that the rock is more vulnerable to failure under the lateral decompression and axial compression environment. Therefore, in actual engineering projects, the surrounding rock of the tunnel is more likely to undergo failure due to brittleness during the process of radial unloading and circumferential loading. This may result in macroscopic failure, such as rib spalling, flaking, or collapse.
3. Dilatancy parameter characteristics. in [27], the concept of the dilatancy index $I_{d}$ was proposed to quantify the shear dilatancy of rocks. It is expressed as follows:

$$
I_{d}=\frac{\theta_{p}}{\theta_{0}}=\frac{\arctan \left(\Delta \varepsilon_{v p} / \Delta \varepsilon_{1 p}\right)_{p}}{\arctan \left(\Delta \varepsilon_{v p} / \Delta \varepsilon_{1 p}\right)_{0}},
$$

where $\theta$ is the apparent expansion angle; $o$ and $p$ indicate the uniaxial and triaxial unloading tests, respectively; and $\Delta \varepsilon_{1 p}$ and $\Delta \varepsilon_{v p}$ are the axial and volumetric plastic strain increments, respectively. For the conventional triaxial unloading test, $\Delta \varepsilon_{v p}=\Delta \varepsilon_{1 p}+2 \Delta \varepsilon_{3 p}$ and $\varepsilon_{p}=\varepsilon-\varepsilon_{e}$, where $\varepsilon_{e}$ is the elastic strain, which can be expressed as $\varepsilon_{e}=\sigma / E$, and $E$ is the unloading elastic modulus. Qiu et al. [28] suggested that $E$ 


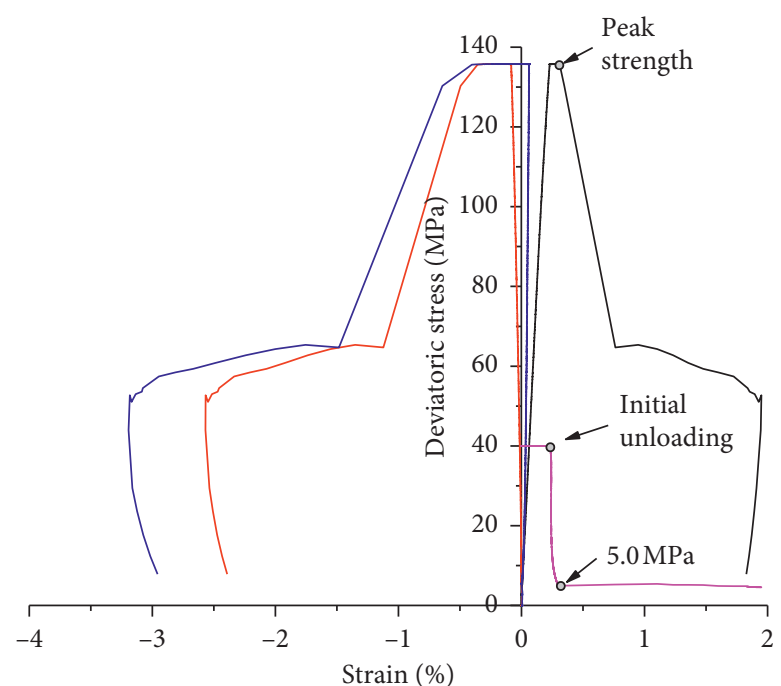

- Axial strain

— Laterial strain

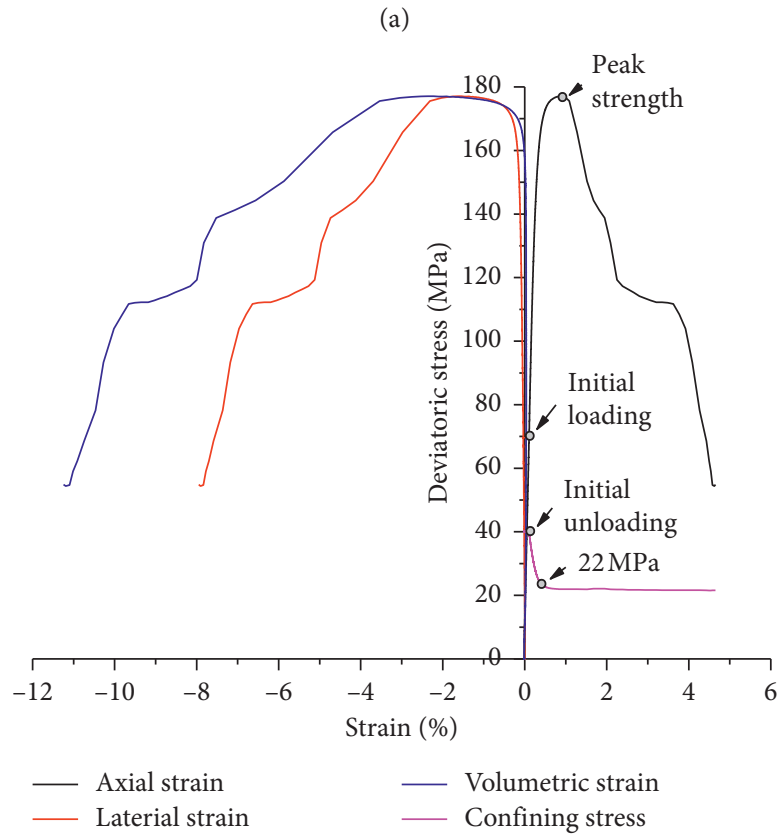

(c)

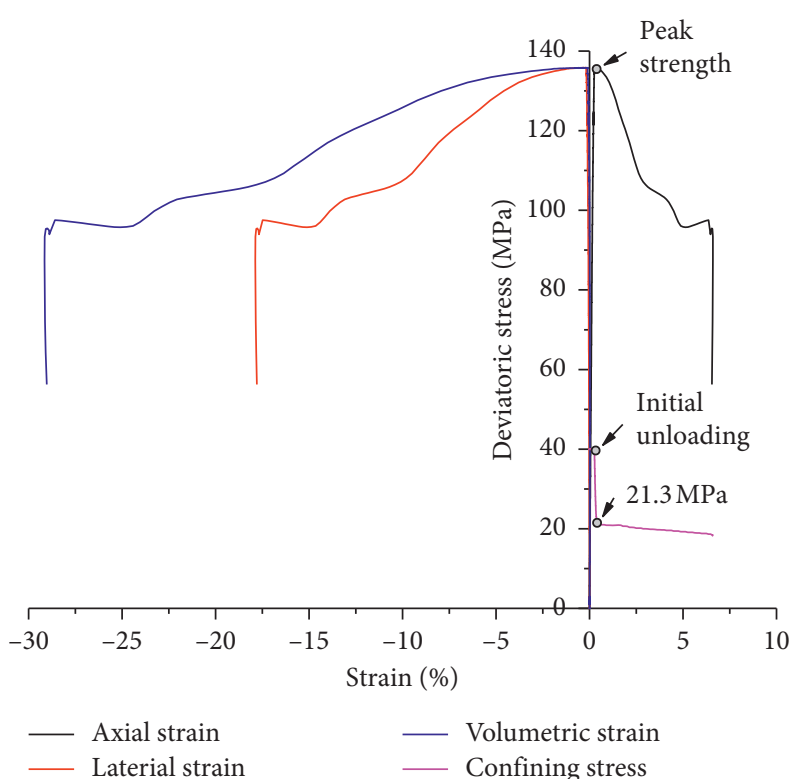

(b)

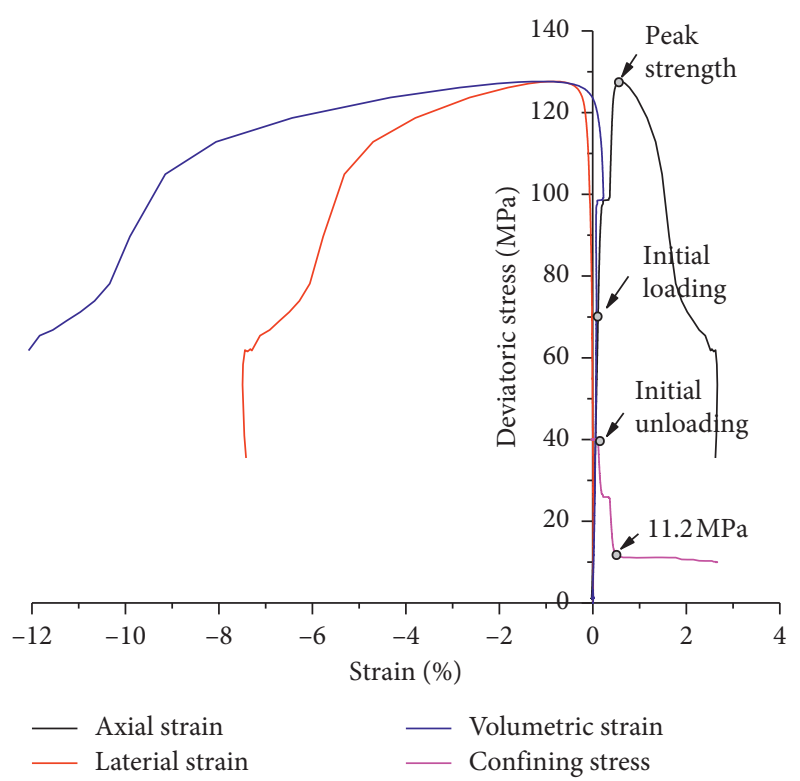

(d)

FiguRE 6: Stress-strain curves in complex loading-unloading stress tests (confining pressure: $40 \mathrm{MPa}$ ): (a) sample 20; (b) sample 22; (c) sample 23; and (d) sample 25.

can approximately take the modulus of the elastic deformation stage of the stress-strain curve. Figure 10 shows the fitting curve between the dilatancy index $I_{d}$ and confining pressure of the marble samples. NU represents the unloading confining pressure path, and LU represents the unloading confining-loading axial pressure stress path.

With the increase in confining pressure, the dilatancy index $I_{d}$ is gradually reduced. It has a good exponential relationship with the confining pressure $\sigma_{3}$, indicating that the increase in confining pressure can effectively restrict the dilatancy of rock samples. Under the same stress path and confining pressure level, with the increase in unloading rates, the dilatancy of rock samples gradually increases, resulting in obvious brittleness. The dilatancy index $I_{d}$ of rock under the unloading confiningloading axial pressure stress path is higher than that under the unloading confining pressure path. Therefore, the brittleness of rock under the loading axial pressure stress path is more obvious. This is consistent with the test results reported in literature [29]. These results also show that, in deep underground caverns, the stress paths experienced at different locations are different. The failure threshold and the degree of damage to the rock samples are also different. 


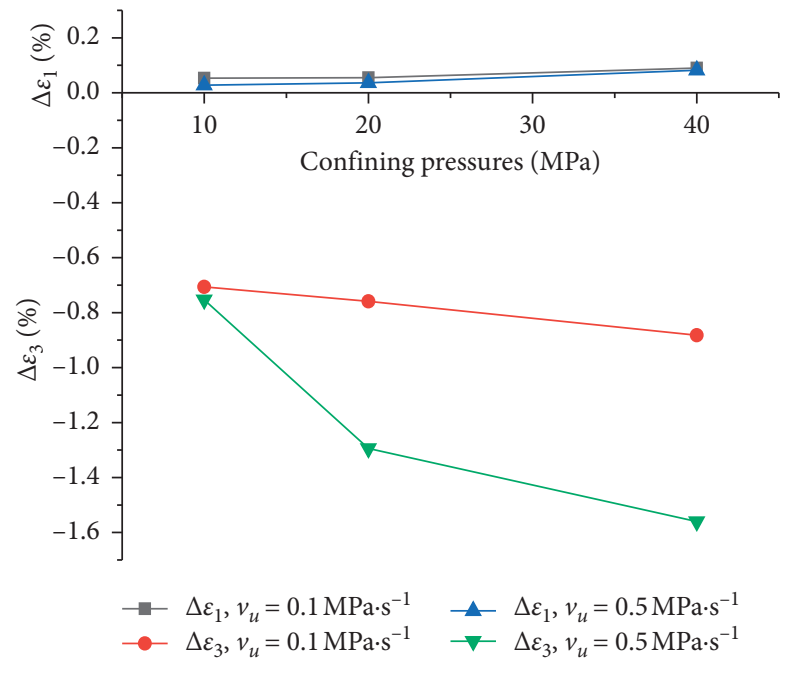

(a)

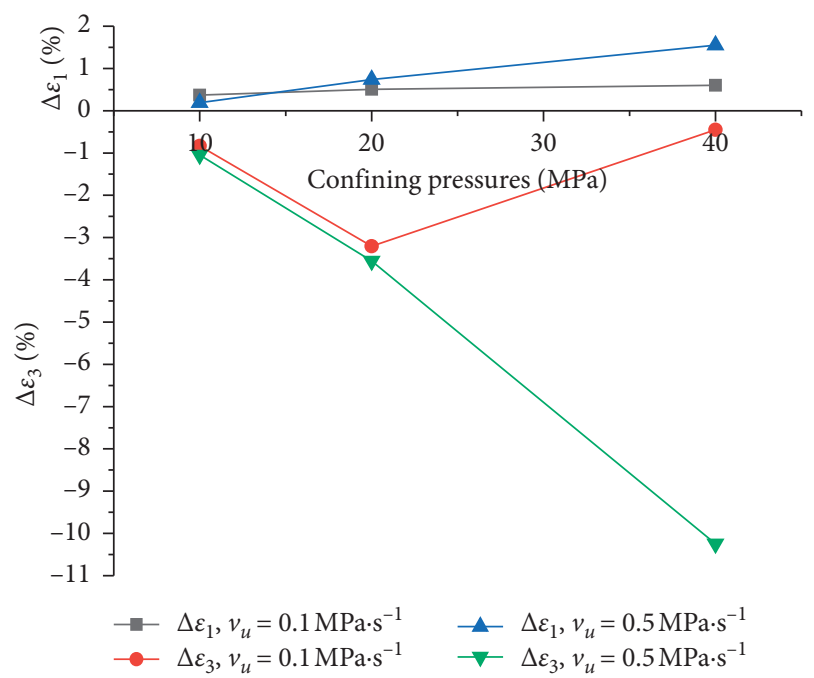

(b)

FIGURE 7: Affection laws of strain increment in the unloading triaxial test: (a) unloading starting point to the peak strength stage; (b) peak strength to the residual strength stage.

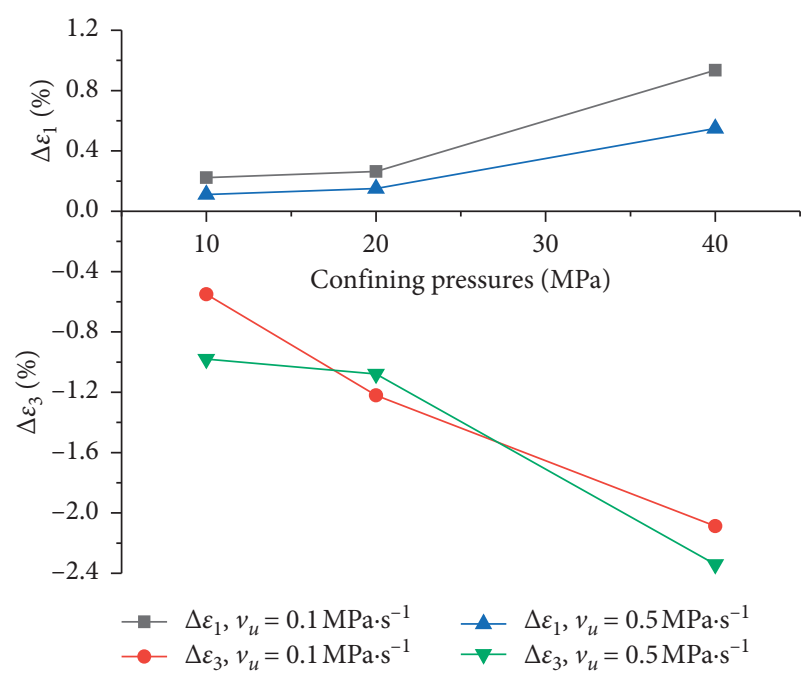

(a)

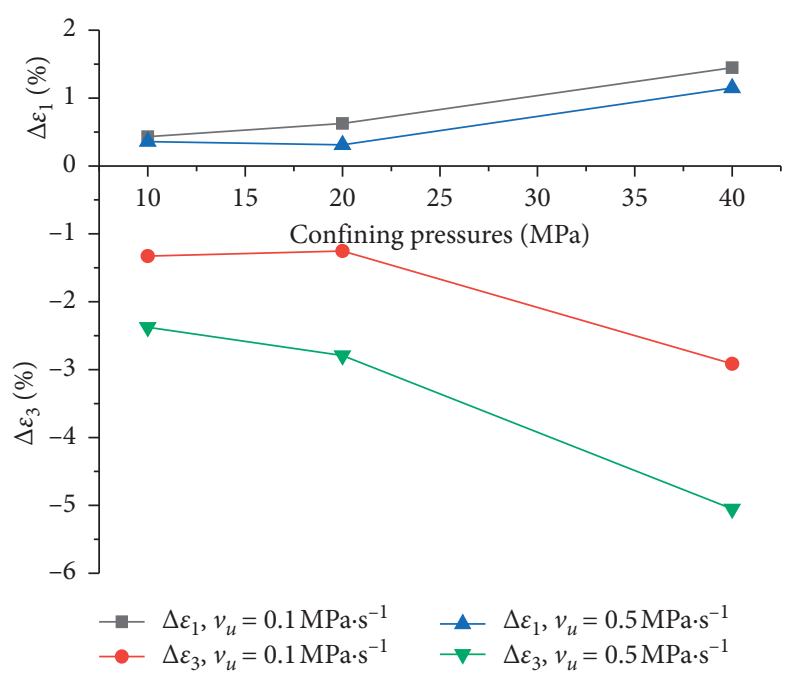

(b)

FIGURE 8: Affection laws of strain increment in the unloading confining-loading axial pressure test: (a) unloading starting point to the peak strength stage; (b) peak strength to the residual strength stage.

3.2.3. Failure Characteristics. Figure 11 shows the typical failure modes of marble samples. The uniaxial test, conventional triaxial compression test, and unloading test show obvious brittleness and significant dilatancy, especially the unloading test.

Different stress path tests show different macroscopic failure modes of rocks. A splitting failure mainly occurs in uniaxial compression tests, and the failure surface and the maximum principal stress surface approximately intersect at a small angle (\#1-\#4) [30]. A simple shear failure occurs in the conventional triaxial compression tests, with scratches and fine rock sample fragments on the fracture surface (\#5, $\# 7$, \#8). The type of failure observed in the unloading test is more complex $[29,31]$. When samples \#11, \#13, and \#17 are destroyed, the confining pressure is $0 \mathrm{MPa}$, indicating that there is no lateral effect at this time. The main failure mode of these samples is tension failure, with a large number of tension failure surfaces observed. When samples \#10, \#12, $\# 14, \# 15$, \#16, \#20, and \#25 are damaged, the corresponding confining pressure is generally less than $15 \mathrm{MPa}$. The main failure mode of these samples is shear failure. There are local tensile damage marks, and a simple macroscopic failure occurs. When samples \#22 and \#23 are damaged, the corresponding failure confining pressure is greater than $15 \mathrm{MPa}$ (18.8 and $22 \mathrm{MPa}$, respectively). Shear failure is still the dominant failure mode, but the failure surface is of the $X$ or $Y$ type. Therefore, the failure state of the rock sample is related to the confining pressure during that failure. When 
TABLE 4: Characteristic stress of rock under complex loading and unloading conditions.

\begin{tabular}{|c|c|c|c|c|c|c|c|c|c|}
\hline \multirow{2}{*}{$\begin{array}{l}\text { Unloading rates } \\
V_{u} \\
\left(\mathrm{MPa} \cdot \mathrm{s}^{-1}\right)\end{array}$} & \multirow[t]{2}{*}{ Confining pressure $(\mathrm{MPa})$} & \multirow[t]{2}{*}{ Sample number } & \multicolumn{3}{|c|}{$\begin{array}{c}\text { Characteristic stress } \\
(\mathrm{MPa})\end{array}$} & \multirow[t]{2}{*}{ Sample number } & \multicolumn{3}{|c|}{$\begin{array}{l}\text { Characteristic stress } \\
\qquad(\mathrm{MPa})\end{array}$} \\
\hline & & & $\sigma_{c d}$ & $\sigma_{f}$ & $\sigma_{r}$ & & $\sigma_{c d}$ & $\sigma_{f}$ & $\sigma_{r}$ \\
\hline \multirow{3}{*}{0.1} & 10 & 10 & 85.31 & 98.82 & 37.81 & 12 & 54.26 & 95.26 & 32.12 \\
\hline & 20 & 14 & 102.19 & 113.5 & 52.87 & 16 & 56.54 & 118.71 & 71.20 \\
\hline & 40 & 20 & 126.63 & 137.3 & 65.17 & 23 & 70.02 & 177.07 & 119.01 \\
\hline \multirow{3}{*}{0.5} & 10 & 11 & 85.31 & 97.86 & 22.39 & 13 & 54.26 & 74.27 & 17.56 \\
\hline & 20 & 15 & 102.19 & 115.85 & 42.55 & 17 & 56.54 & 105.74 & 18.37 \\
\hline & 40 & 22 & 126.64 & 138.14 & 104.91 & 25 & 70.02 & 127.61 & 78.56 \\
\hline
\end{tabular}

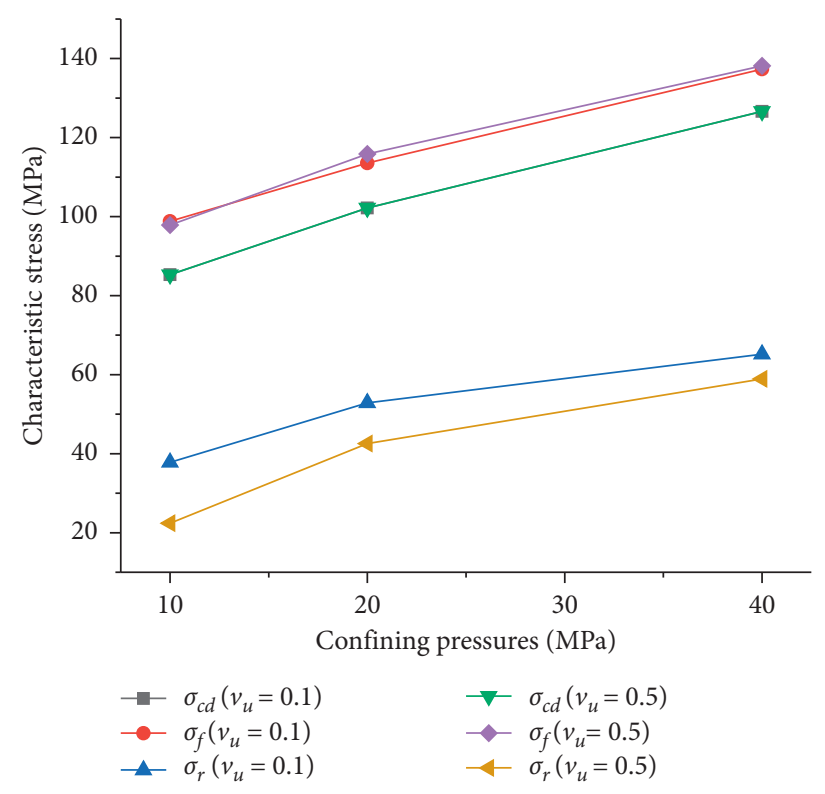

(a)

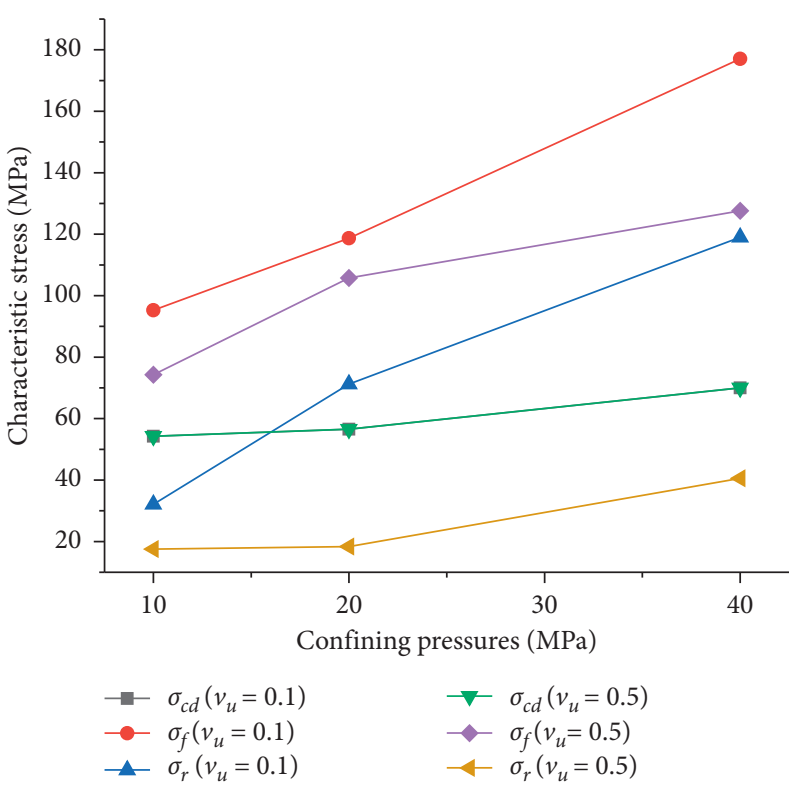

(b)

FIgURE 9: Affection laws of characteristic stress under complex loading and unloading conditions: (a) unloading triaxial test; (b) unloading confining-loading axial pressure test.

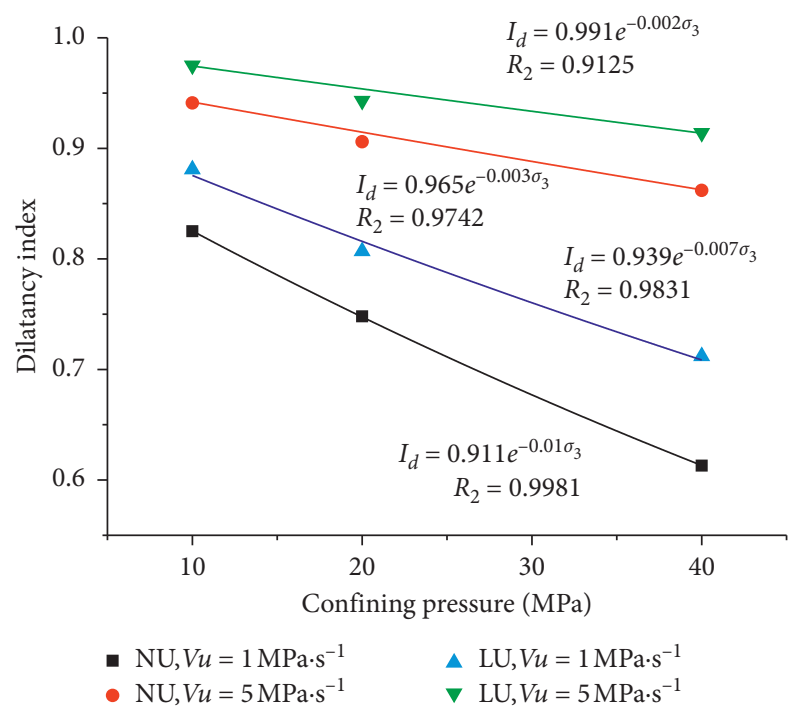

FIGURE 10: Relationship between the dilatancy index and confining pressure. there is no lateral action, tensile failure generally occurs in the rock. When there is a lateral action, shear failure is dominant.

3.2.4. Energy Characteristics. Rock failure is a state instability phenomenon driven by energy. In the unloading confining pressure test, the axial compression deformation absorbs strain energy, while lateral expansion deformation consumes strain energy. According to literature [10], the total strain energy $U_{0}$ of rock samples in the conventional triaxial compression test can be expressed as

$$
\begin{array}{r}
U_{0}=U_{1}+U_{3}=\int \sigma_{1} \mathrm{~d} \varepsilon_{1}+2 \int \sigma_{3} \mathrm{~d} \varepsilon_{3}=U_{e}+U_{d}, \\
U_{e}=\frac{1}{2 \bar{E}}\left[\sigma_{1}^{2}+2 \sigma_{3}^{2}-2 \bar{v} \sigma_{3}\left(2 \sigma_{1}+\sigma_{3}\right)\right],
\end{array}
$$

where $U_{1}$ is the strain energy absorbed by the axial compression of $\sigma_{1} ; U_{3}$ is the strain energy consumed by the negative work of $\sigma_{3} ; U_{e}$ is the released elastic strain energy; 


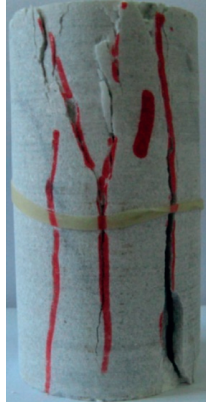

(a)

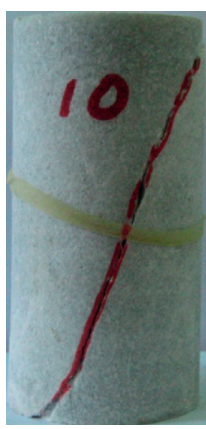

(h)

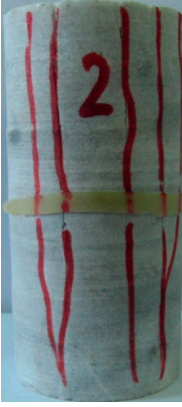

(b)

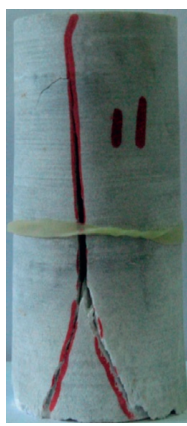

(i)

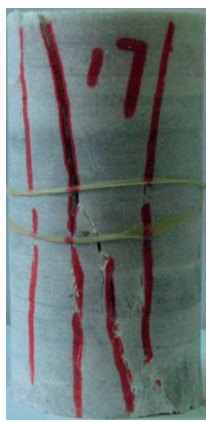

(o)

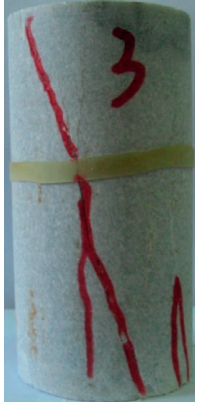

(c)

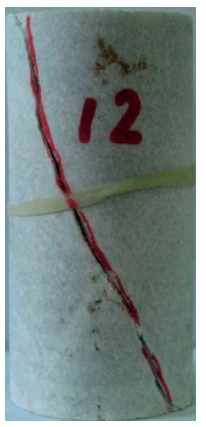

(j)

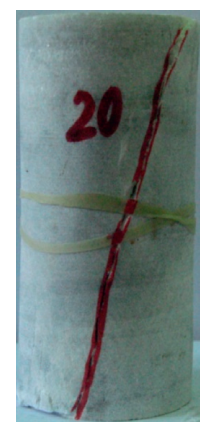

(p)

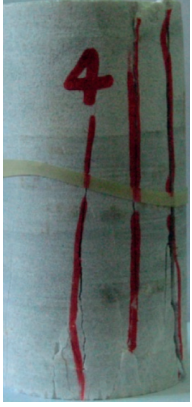

(d)

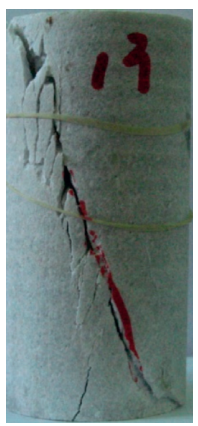

(k)

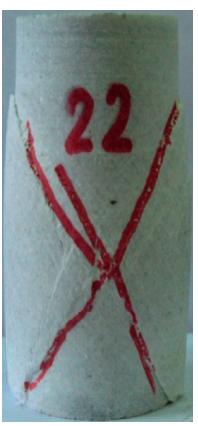

(q)

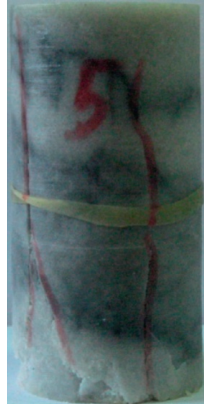

(e)

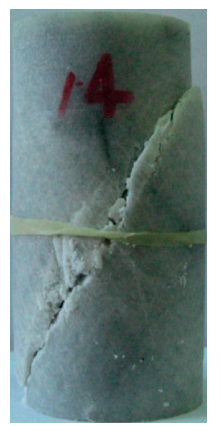

(l)

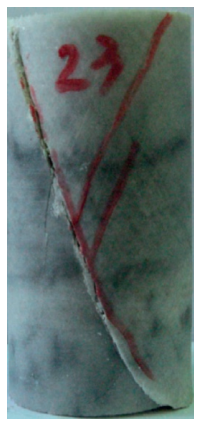

(r)

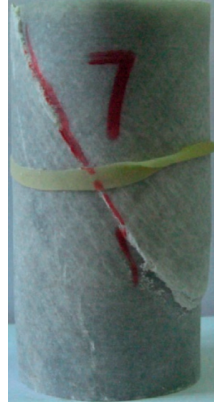

(f)

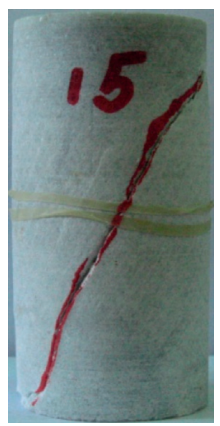

(m)

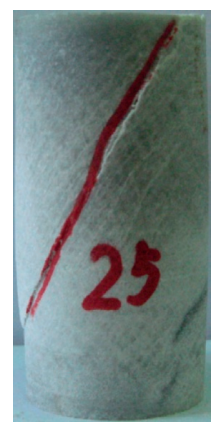

(s)

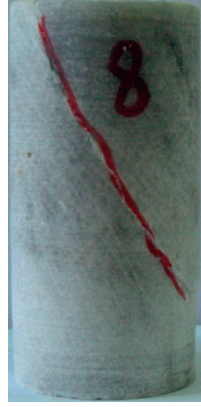

(g)

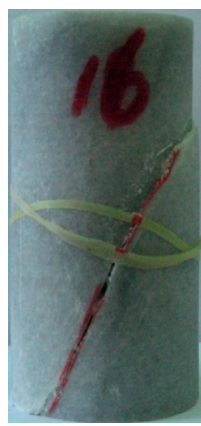

(n)

Figure 11: Failure modes of marble specimens: (a) \#1; (b) \#2; (c) \#3; (d) \#4; (e) \#5; (f) \#7; (g) \#8; (h) \#10; (i) \#11; (j) \#12; (k)\#13; (l) \#14; (m) $\# 15$; (n) \#16; (o) \#17; (p) \#20; (q) \#22; (r) \#23; and (s) \#25.

$U_{d}$ is the dissipated energy; and $\mu$ and $E$ are average Poisson's ratio and the unloading elastic modulus, respectively.

1. Energy conversion process: during the unloading test, the strain energy conversion is accompanied by crack initiation, propagation, and penetration. Figure 12 shows the typical strain energy variation curves under the unloading pressure condition (sample 15). The energy conversion process can be divided into three stages.

(1) Within the compaction and elastic parts of the early stage of the loading process, there is obvious energy accumulation. The total energy absorbed by rock samples is mainly converted to stored elastic strain energy, and the increase in dissipated energy is relatively slow, which is mainly due to the compaction of rock samples and the formation of local microcracks.

(2) Within the nonlinear deformation stage from the unloading starting point to the peak strength, the deviatoric stress of rock samples increases.
Meanwhile, the absorbed strain energy $U_{1}$ increases rapidly, and the elastic energy $U_{e}$ remains basically unchanged. The dissipated strain energy $U_{d}$ increases near the peak point due to the rapid propagation of internal cracks, but most of the energy is still stored in the form of elastic strain energy; the elastic strain energy is mainly stored before the peak strength.

(3) After the peak strength, the lateral strain increases further, resulting in the occurrence and propagation of macroscopic cracks. The elastic strain energy $U_{e}$ decreases gradually, while the lateral deformation dissipation strain energy $U_{3}$ continues to decrease. The dissipated energy $U_{d}$ increases rapidly and gradually becomes higher than the elastic energy. This continues until the rock sample is damaged, which is characterized by tensile rupture or splitting nearly perpendicular to the direction of unloading. 

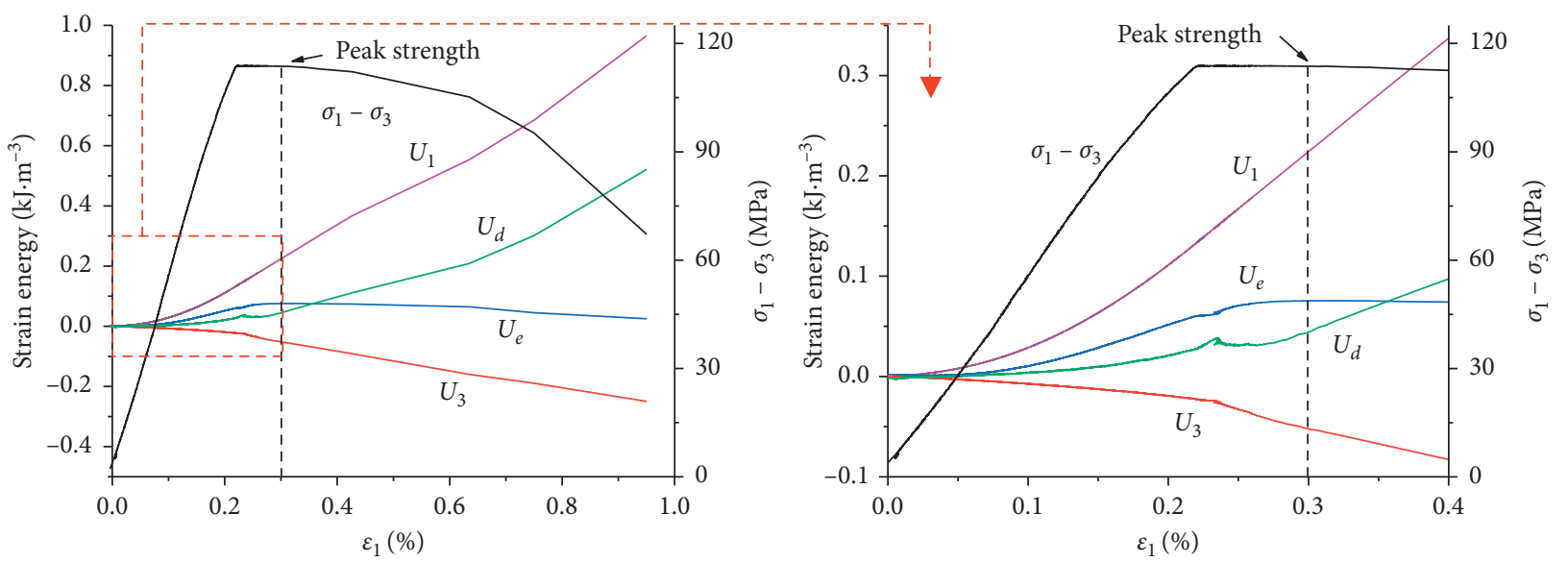

Figure 12: Typical strain energy curves from unloading tests (sample 15).

2. Characteristic energy: Figures 13 and 14 show the variations in peak and residual energy under different unloading conditions. The following is observed:

(1) With the increase in confining pressure, both peak and residual energy increase. This indicates that a high confining pressure limits crack propagation and further increases the deviatoric stress, resulting in the increase in stored energy so that less energy is needed to reach the residual strength after the peak strength.

(2) The unloading rate has a great influence on energy conversion. Under the same stress path, the peak and residual strain energy are lower with higher unloading rates. With the increase in the unloading rate, the energy required for rock failure is less, and the samples show obvious brittleness. The processes of generation, propagation, and penetration of microcracks are not completed in sufficient time, leading to less accumulation and dissipation of strain energy.

(3) The characteristic energy varies with different stress paths. Under the residual strength condition, the elastic strain energy $U_{e}$ is lower than the dissipated energy $U_{d}$, and the difference between the two values is large. Under the peak strength condition, $U_{e}$ and $U_{d}$ are close to each other, and there is a great difference in peak energy under different paths. Under the unloading confining pressure path, the peak energy is less, and $U_{e}>U_{d}$. Under the unloading confining-loading axial pressure stress path, the energy is relatively large, and $U_{e}<U_{d}$. This indicates that, during the process of loading axial pressure, due to the initial axial stress being small, the rock needs to absorb more energy from the outside to further stimulate crack generation, propagation, and penetration before the peak strength and further increase the dissipated energy.

3.2.5. Strength Characteristics. A large number of test results show that the Mohr-Coulomb criterion is ineffective in characterizing the failure strength of unloading rock under high confining pressure. Using its improved form, that is, the Mogi-Coulomb criterion [6], rock strength under the complex loading and unloading stress paths is studied. For the conventional triaxial test, $\sigma_{2}=\sigma_{3}$. The expression is as follows:

$$
\tau_{\text {oct }}=f\left(\sigma_{m, 2}\right)
$$

Here,

$$
\begin{aligned}
\sigma_{m, 2} & =\frac{\sigma_{1}+\sigma_{3}}{2}, \\
\tau_{\text {oct }} & =\frac{\sqrt{2}}{3}\left(\sigma_{1}-\sigma_{3}\right),
\end{aligned}
$$

where $\tau_{\text {oct }}$ is the octahedral shear stress and $\sigma_{m, 2}$ is the effective intermediate principal stress. In [32], the linear relationship between $\tau_{\text {oct }}$ and $\sigma_{m, 2}$ is proposed:

$$
\tau_{\mathrm{oct}}=a+b \sigma_{m, 2}
$$

where $a$ and $b$ are the linear parameters of the Mogi-Coulomb criterion. The relations between the cohesion force $c$ and the internal friction angle $\varphi$ are as follows:

$$
\begin{aligned}
& a=\frac{2 \sqrt{2}}{3} c \cos \varphi, \\
& b=\frac{2 \sqrt{2}}{3} c \sin \varphi .
\end{aligned}
$$

Figures 15 and 16 are the fitting curves of unloading rock strength based on the Mohr-Coulomb criterion and the Mogi-Coulomb criterion, respectively. It can be seen that when the Mogi-Coulomb criterion is used for fitting, the correlation coefficient, $R^{2}$, is higher than that of the Mohr-Coulomb criterion. So, the Mogi-Coulomb criterion can be better applied to the study of rock failure under high confining pressure.

Most of the strength criteria currently used are based on elastic strain energy, but it is believed that only when $U_{e}$ reaches a certain critical value and $\nu=0.5$ [21] does the material begin to yield or be destroyed. This limits its 


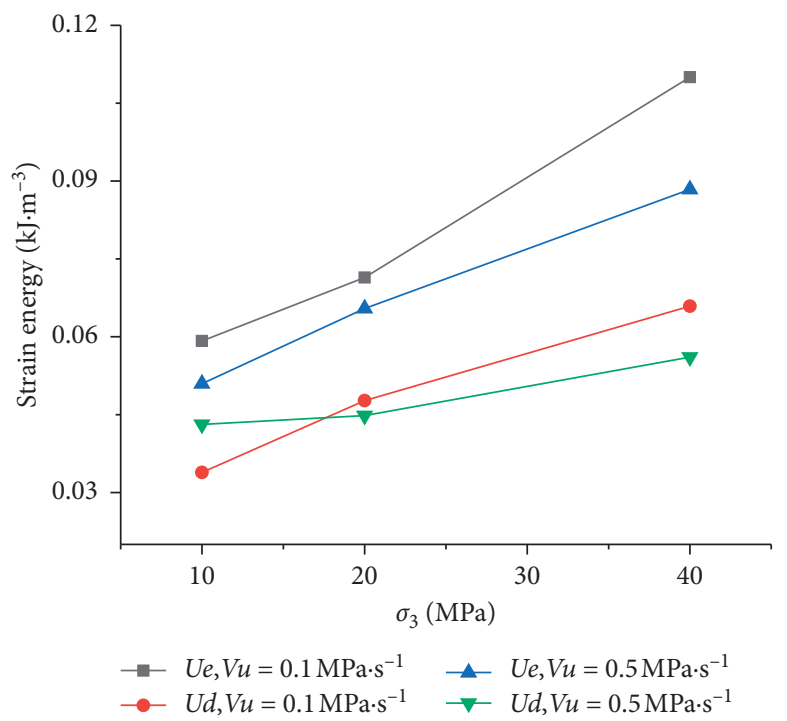

(a)

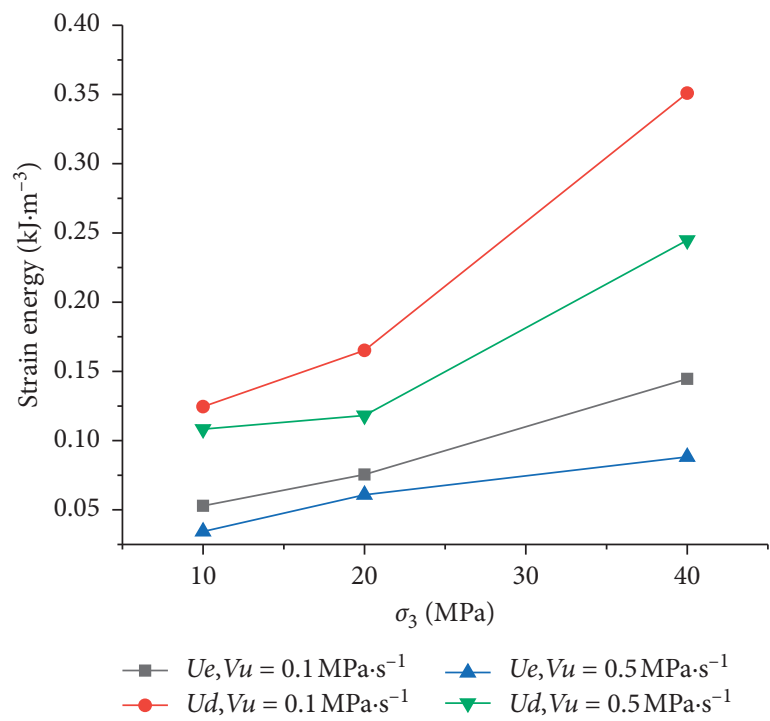

(b)

FIGURE 13: Strain energy eigenvalue curves of the unloading test at peak strength: (a) unloading triaxial test; (b) unloading confining-loading axial pressure test.

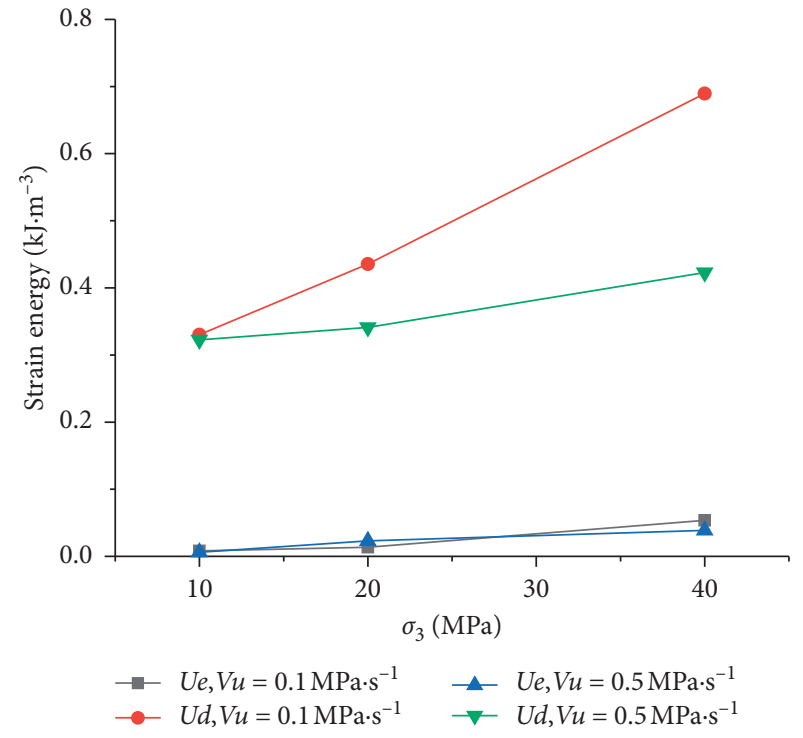

(a)

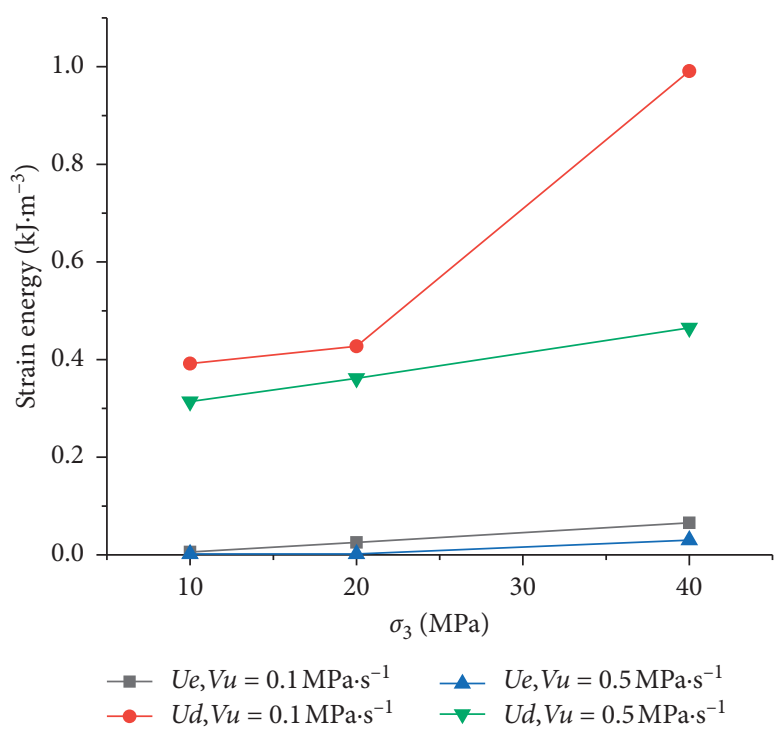

(b)

FIGURE 14: Strain energy eigenvalue curves of the unloading test at residual strength: (a) unloading triaxial test; (b) unloading confiningloading axial pressure test.

application in the study of mechanical characteristics of unloading rocks. For example, the Mohr-Coulomb criterion cannot reflect the influence of the intermediate principal stress of rock and cannot reveal the intrinsic mechanism of energy conversion during rock failure.

Guo et al. [21] considered the crack propagation phenomenon of unloading rock mass in the yield or failure state $(\nu>0.5)$, regarded Poisson's ratio as a material parameter related to the stress state, and studied the fundamental reasons of rock yield and failure during the unloading process based on the elastic strain energy. Taking the maximum energy storage hypothesis Drucker-Prager criterion as an example, based on the physical significance of the existing strength criterion, and considering that when $U_{e}$ reaches a certain critical value, the material begins to yield and be destroyed, the elastic strain energy strength criterion (equation (7)) was proposed. The failure strength of Jinping marble under complex loading and unloading stress paths was studied by using this criterion, as shown in Figure 17.

$$
\sqrt{J_{2}^{g}}=\left(\alpha I_{1}+k\right)
$$




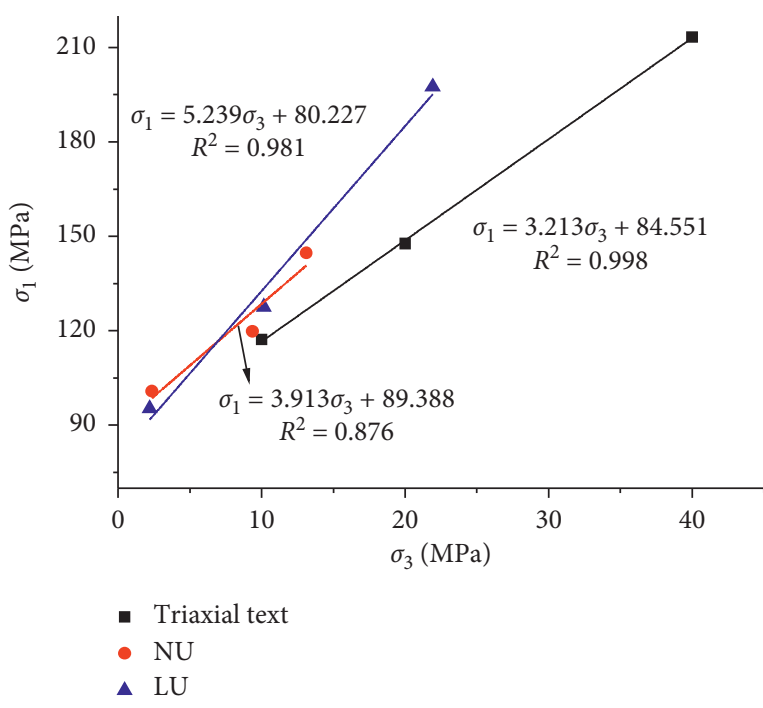

(a)

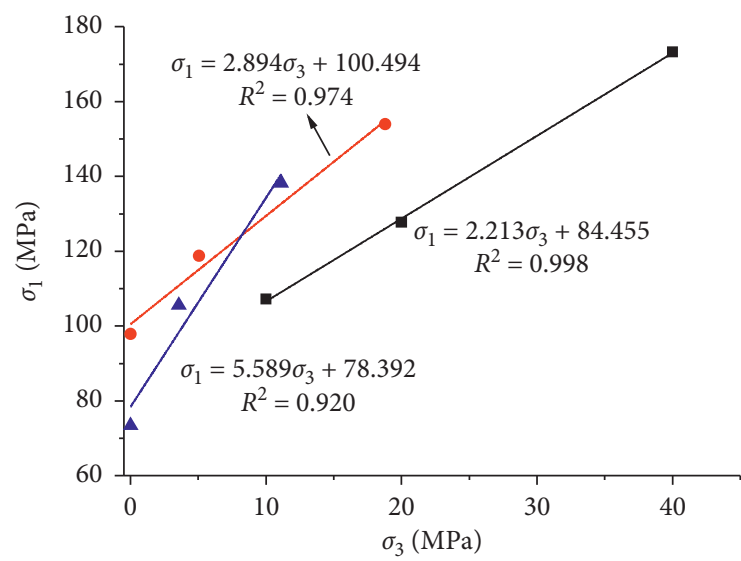

- Triaxial text

- NU

^ LU

Figure 15: Mohr-Coulomb criterion: (a) $V_{u}=0.1 \mathrm{MPa} \mathrm{s}^{-1}$; (b) $V_{u}=0.5 \mathrm{MPa} \mathrm{s}^{-1}$.

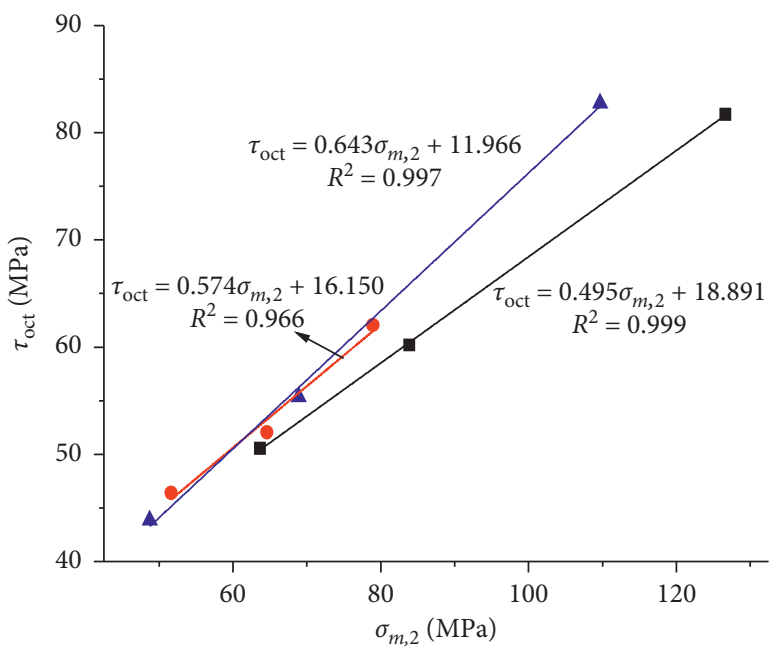

- Triaxial text

- NU

$\Delta \mathrm{LU}$

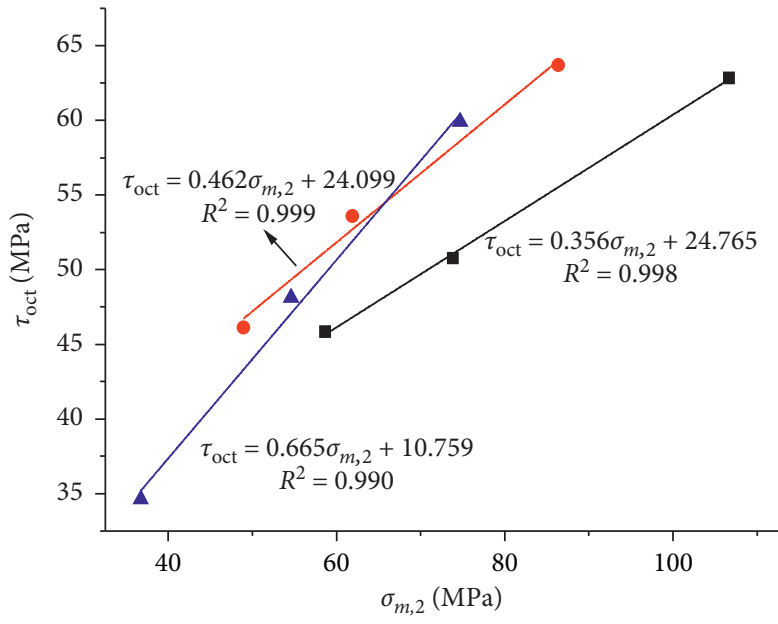

- Triaxial text

- $\mathrm{NU}$

- LU

(a)

(b)

Figure 16: Mogi-Coulomb criterion: (a) $V_{u}=0.1 \mathrm{MPa} \mathrm{s}^{-1}$; (b) $V_{u}=0.5 \mathrm{MPa} \mathrm{s}^{-1}$.

It can be concluded from Figure 17 that the correlation coefficient of the fitting curve based on the elastic strain energy strength criterion is relatively high and can present the strength characteristics of the unloading rock sample well. Moreover, the criterion can describe the following phenomenon: "when the confining pressure is less than (greater than) a critical value, the peak strength of unloaded rock is lower than (higher than) the peak strength of loaded rock under the same confining pressure condition." Compared with the Mogi-Coulomb criterion and Mohr-Coulomb criterion, this result is more consistent with the mechanical characteristics of rock mass in actual engineering projects.

In this paper, the main influence factors such as stress paths, initial confining pressure, and unloading rates are discussed, and the mechanical properties of unloading rock are systematically expressed. However, the deficiency of our theory is that only two initial unloading levels are designed based on the two test schemes; that is, the unloading point is $50 \%$ and $85 \%$ of the ultimate load when loading and unloading the axial pressure, respectively. It is necessary to further study the unloading rock 


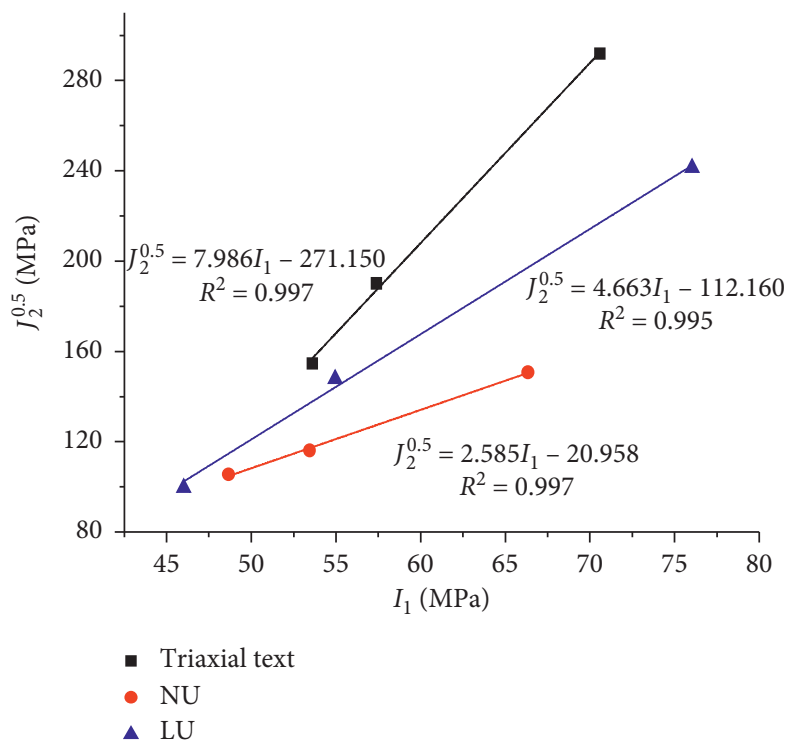

(a)

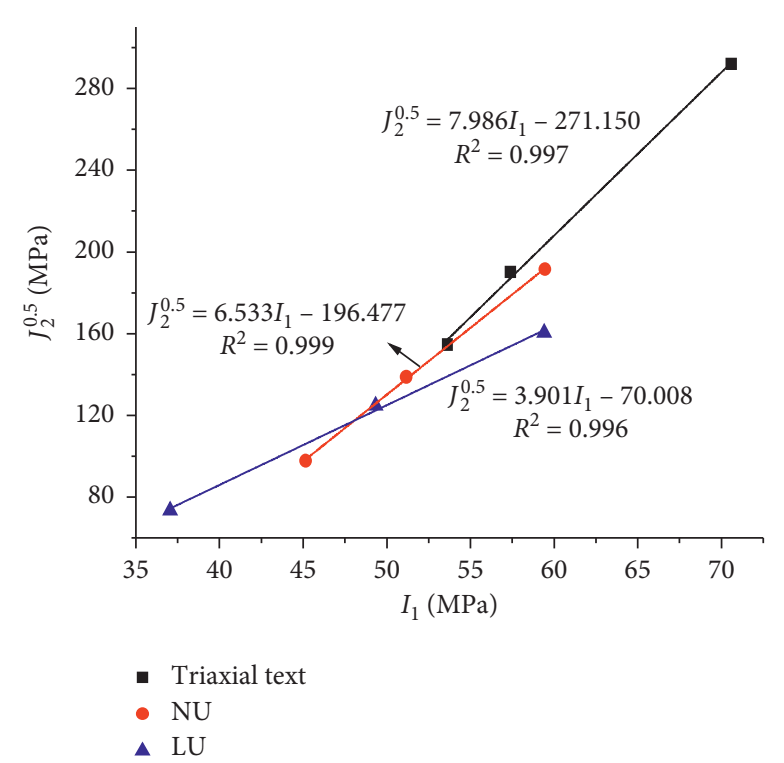

(b)

Figure 17: Strength criterion based on elastic strain energy: (a) $V_{u}=0.1 \mathrm{MPa} \mathrm{s}^{-1}$; (b) $V_{u}=0.5 \mathrm{MPa} \mathrm{s}^{-1}$.

under different initial unloading levels. At the same time, the mechanical properties of deep rock are obviously affected by the hydraulic pressure, which has been shown in $[33,34]$, but is not investigated in this study. The unloading process of deep rock is complex, and a more comprehensive study on the influence factors of unloading rock would be an emphasis in the future. In this way, the laboratory tests are more consistent with the engineering practice, which provide a more reliable basis for the excavation of deep tunnels.

\section{Conclusions}

(1) The conventional triaxial compression tests of Jinping marble present typical elasto-brittle-plastic characteristics, while the complex loading and unloading stress tests show obvious elastobrittle characteristics.

(2) The lateral strain increment of unloading failure is much larger than that of axial strain, which indicates that the lateral expansion is obvious, and the rock failure is the result of intensive dilatancy. The strain increment after the peak strength is significantly higher than that before the peak strength, and the dilatancy of the rock increases by the propagation of microcracks. With the increase in the unloading rate and initial unloading confining pressure, the lateral strain increment increases gradually, and the dilatancy becomes obvious.

(3) The initial yield stress, peak stress, and residual stress increase with the increase in confining pressure. The peak and residual stress are lower with larger unloading rates. This indicates that the increase in unloading rates accelerates the formation of a fracture and decreases the bearing capacity of the rock. The dilatancy index decreases gradually with an increasing confining pressure and a lower unloading rate and has a good exponential relationship with the confining pressure. The dilatancy index of the rock under the unloading confining-loading axial pressure stress path is relatively large; that is to say, the brittleness of this stress path is more obvious.

(4) The absorbed strain energy increases rapidly and is mainly stored in the form of elastic energy $U_{e}$ before the peak strength. Meanwhile, the dissipated energy $U_{d}$ increases obviously close to the peak point, until the rock sample is damaged. The peak and residual energy increase with a higher confining pressure. The characteristic energy is lower with the larger unloading rates. This is due to less energy being required for rock failure with the larger unloading rate. In addition, under the unloading confining pressure path, the peak energy is less, and $U e>U_{d}$. Under the unloading confining-loading axial pressure stress path, the energy is relatively large, and $U_{e}<U_{d}$. This indicates that, during the process of loading axial pressure, due to the lower initial axial stress, the rock needs to absorb more energy from the outside to stimulate crack generation, propagation, and penetration before the peak strength and further increase the dissipated energy.

(5) The Mogi-Coulomb strength criterion is better applied to the study of rock unloading failure than the Mohr-Coulomb strength criterion under the complex loading and unloading stress conditions. The elastic strain energy strength criterion considers that Poisson's ratio can be greater than 0.5 when the material is destroyed, which is more consistent with the yield or failure state of unloading rock mass. 


\section{Data Availability}

The datasets used or analyzed during the current study are available from the corresponding author upon reasonable request.

\section{Conflicts of Interest}

The authors declare that there are no conflicts of interest regarding the publication of this paper.

\section{Acknowledgments}

This work was supported by the National Nature Science Foundation of China (Nos. 51609266 and 51879284).

\section{References}

[1] S. L. Qiu, X. T. Feng, C. Q. Zhuang, and J. B. Yang, "Experimental research on mechanical properties of deep marble under different initial damage levels and unloading paths," Chinese Journal of Rock Mechanics and Engineering, vol. 31, pp. 1686-1697, 2012.

[2] P. K. Kaiser, S. Yazici, and S. Maloney, "Mining-induced stress change and consequences of stress path on excavation stability-a case study," International Journal of Rock Mechanics and Mining Sciences, vol. 38, no. 2, pp. 167-180, 2001.

[3] C. D. Martin and R. Christiansson, "Estimating the potential for spalling around a deep nuclear waste repository in crystalline rock," International Journal of Rock Mechanics and Mining Sciences, vol. 46, no. 2, pp. 219-228, 2009.

[4] C. D. Martin, R. S. Read, and J. B. Martino, "Observations of brittle failure around a circular test tunnel," International Journal of Rock Mechanics and Mining Sciences, vol. 34, pp. 1065-1073, 1997.

[5] Q. Yu, C. A. Tang, L. C. Li, H. Li, and G. W. Cheng, "Nucleation process of rockbursts based on microseismic monitoring of deep-buried tunnels for Jinping II Hydropower Station," Chinese Journal of Geotechnical Engineering, vol. 36, pp. 2315-2322, 2013.

[6] D. Y. Li, Z. Sun, X. B. Li, and T. Xie, "Mechanical response and failure characteristics of granite under different stress paths in triaxial loading and unloading conditions," Chinese Journal of Rock Mechanics and Engineering, vol. 35, pp. 3449-3457, 2016.

[7] R. Q. Huang and D. Huang, "Experimental research on affection laws of unloading rates on mechanical properties of Jinping marble under high geostress," Chinese Journal of Rock Mechanics and Engineering, vol. 29, pp. 21-33, 2010.

[8] Q. B. Meng, M. W. Zhang, L. J. Han, H. Pu, and T. Y. Nei, "Effects of acoustic emission and energy evolution of rock specimens under the uniaxial cyclic loading and unloading compression," Rock Mechanics and Rock Engineering, vol. 49, pp. 1-14, 2016.

[9] X. G. Zhao, J. Wang, M. Cai et al., "Influence of unloading rate on the strainburst characteristics of Beishan granite under true-triaxial unloading conditions," Rock Mechanics and Rock Engineering, vol. 47, no. 2, pp. 467-483, 2014.

[10] D. Huang and Y. Li, "Conversion of strain energy in triaxial unloading tests on marble," International Journal of Rock Mechanics and Mining Sciences, vol. 66, pp. 160-168, 2014.

[11] E. Gaziev, "Rupture energy evaluation for brittle materials," International Journal of Solids and Structures, vol. 38, no. 4243, pp. 7681-7690, 2001.
[12] C. E. Tsouthrelis and G. E. Exadaktylos, "Effect of Rock discontinuities on certain rock strength and fracture energy parameters under uniaxial compression," Geotechnical and Geological Engineering, vol. 11, pp. 81-105, 1993.

[13] A.-Z. Hua and M.-Q. You, "Rock failure due to energy release during unloading and application to underground rock burst control," Tunnelling and Underground Space Technology, vol. 16, no. 3, pp. 241-246, 2001.

[14] Y. Nara and K. Kaneko, "Sub-critical crack growth in anisotropic rock," International Journal of Rock Mechanics and Mining Sciences, vol. 43, no. 3, pp. 437-453, 2006.

[15] H. P. Xie, Y. Ju, and L. Y. Li, "Criteria for strength and structure failure of rocks based on energy dissipation and energy release principles," Chinese Journal of Rock Mechanics and Engineering, vol. 24, pp. 3003-3010, 2005.

[16] Y. F. Gao and Z. Y. Tao, "Examination and analysis of true triaxial compression testing of strength criteria of rock," Chinese Journal of Geotechnical Engineering, vol. 15, pp. 2632, 1993.

[17] G. Y. Zhao, B. Dai, L. J. Dong, and C. Yang, "Experimental research on mechanical characteristics and strength criterion of rock of triaxial unloading tests under different stress paths," Rock and Soil Mechanics, vol. 36, pp. 3121-3127, 2015.

[18] W. S. Xu, G. M. Zhao, X. R. Meng, and X. Cheng, "Modified $\mathrm{D}-\mathrm{P}$ criterion based on the double-fold reduction method of the true triaxial single-side unloading strength," Chinese Journal of Rock Mechanics and Engineering, vol. 341, pp. 42-51, 2018.

[19] S. J. Miao, Z. J. Yang, C. Long, and W. H. Tan, "Equivalent plastic parameters optimization research on CWFS failure criterion model of brittle hard rock," Chinese Journal of Rock Mechanics and Engineering, vol. 31, pp. 2600-2605, 2013.

[20] L. Qiao, W. Gao, Y. Li, and Z. J. Yang, "Improved CWFS model for hard rocks and its application to stability analysis of high rock slope," Chinese Journal of Rock Mechanics and Engineering, vol. 31, pp. 2593-2600, 2012.

[21] J. Q. Guo, X. R. Liu, and Q. Zhao, "Theoretical research on rock unloading mechanical characteristics," Rock and Soil Mechanics, vol. 38, pp. 123-130, 2017.

[22] E. Hoek and E. T. Brown, Underground Excavations In Rock, pp. 320-470, Institution of Mining \& Metallurgy, London, UK, 1982.

[23] F.-q. Gong, Y. Luo, X.-b. Li, X.-f. Si, and M. Tao, "Experimental simulation investigation on rockburst induced by spalling failure in deep circular tunnels," Tunnelling and Underground Space Technology, vol. 81, pp. 413-427, 2018.

[24] L. P. Liu, X. G. Wang, Z. X. Jia, Q. W. Duan, and L. Jia, "Tunnel face advancing on development of stress and microfracture around excavation," Journal of Central South University, vol. 44, pp. 764-771, 2013.

[25] H. Z. Li, C. C. Xia, Z. J. Yan, K. Jiang, and L. D. Yang, "Study of marble unloading mechanical properties of Jinping hydropower station under high geostress conditions," Chinese Journal of Rock Mechanics and Engineering, vol. 26, pp. 2104-2109, 2007.

[26] B. Wang, J. B. Zhu, A. Q. Wu, J. M. Hu, and Z. M. Xiong, "Experimental study on mechanical properties of Jinping marble under loading and unloading stress paths," Chinese Journal of Rock Mechanics and Engineering, vol. 27, pp. 2138-2145, 2008.

[27] Y. R. Yang, H. Q. Xie, M. S. Xiao, J. F. Liu, and H. D. Jiang, "Dilatancy and energy characteristics analysis of transverseisotropic rock mass under triaxial unloading condition," Rock and Soil Mechanics, vol. 38, pp. 1589-1599, 2017. 
[28] S.-L. Qiu, X.-T. Feng, J.-Q. Xiao, and C.-Q. Zhang, “An experimental study on the pre-peak unloading damage evolution of marble," Rock Mechanics and Rock Engineering, vol. 47, no. 2, pp. 401-419, 2014.

[29] L. P. Liu, X. G. Wang, Z. X. Jia, Q. W. Duan, and L. Zhang, "Experiment study of marble mechanical properties in Jinping II hydropower station under complex loading and unloading conditions," Rock and Soil Mechanics, vol. 34, pp. 2287-2294, 2013.

[30] F. Gong, J. Yan, S. Luo, and X. Li, "Investigation on the linear energy storage and dissipation laws of rock materials under uniaxial compression," Rock Mechanics and Rock Engineering, vol. 52, no. 11, pp. 4237-4255, 2019.

[31] X. Si and F. Gong, "Strength-weakening effect and sheartension failure mode transformation mechanism of rockburst for fine-grained granite under triaxial unloading compression," International Journal of Rock Mechanics and Mining Sciences, vol. 131, p. 104347, 2020.

[32] A. M. Al-Ajmi and R. W. Zimmerman, "Relation between the Mogi and the coulomb failure criteria," International Journal of Rock Mechanics and Mining Sciences, vol. 42, pp. 431-439, 2005.

[33] X. R. Liu, J. Liu, H. Feng, L. B. Du, C. M. He, and Z. L. Zhong, "Experimental research on unloading mechanical properties of sandstone under different initial unloading levels and pore pressures," Chinese Journal of Geotechnical Engineering, vol. 40, pp. 1143-1151, 2018.

[34] H. Tang, T. B. Li, G. Q. Chen, and Y. K. Wang, "Triaxial unloading tests on rupture characteristics of sandstone under hydro-mechanical coupling conditions," Chinese Journal of Geotechnical Engineering, vol. 37, pp. 519-525, 2015. 